\title{
Endosialin is expressed in high grade and advanced sarcomas: Evidence from clinical specimens and preclinical modeling
}

\author{
CECILE ROULEAU ${ }^{1}$, ROBERT SMALE ${ }^{2}$, YAO-SHI FU ${ }^{2}$, GUODONG HUI $^{1}$, FEI WANG ${ }^{1}$, \\ ELIZABETH HUTTO $^{1}$, ROBERT FOGLE ${ }^{1}$, CRAIG M. JONES ${ }^{1}$, ROY KRUMBHOLZ ${ }^{3}$, \\ STEPHANIE ROTH ${ }^{3}$, MARITZA CURIEL ${ }^{2}$, YI REN ${ }^{1}$, REBECCA G. BAGLEY ${ }^{1}$, GINA WALLAR ${ }^{2}$, \\ GLENN MILLER $^{2}$, STEVEN SCHMID $^{3}$, BRUCE HORTEN ${ }^{4}$ and BEVERLY A. TEICHER ${ }^{1,5}$ \\ ${ }^{1}$ Genzyme Corporation, Framingham, MA; ${ }^{2}$ Genzyme Genetics, Los Angeles, CA; \\ ${ }^{3}$ Genzyme Corporation, San Antonio, TX; ${ }^{4}$ Genzyme Genetics, New York, NY, USA
}

Received February 28, 2011; Accepted March 21, 2011

DOI: $10.3892 /$ ijo.2011.1020

\begin{abstract}
We previously surveyed the expression of endosialin/ CD248/TEM-1 by immunohistochemistry in human clinical specimens of sarcomas and documented expression in tumor cells, stromal cells and vasculature. In the present study, we completed a retrospective analysis of the diagnostic reports available for these same samples in order to identify high-grade and metastatic disease. Our results show that endosialin can be detected in advanced disease. We screened human sarcoma cell lines in vitro for endosialin expression and developed preclinical human xenograft models of disseminated sarcoma. We found that 22 out of 42 human sarcoma cell lines were positive for endosialin with a positive correlation between mRNA and protein levels. When implanted in vivo, endosialin was expressed at all sites of dissemination. These data provide clinical and preclinical evidence that endosialin can be detected in advanced sarcoma. These results demonstrate for the first time that endosialin is a suitable therapeutic target for poor prognosis and advanced disease.
\end{abstract}

\section{Introduction}

Sarcomas are cancers of mesodermal origin that arise from connective tissue (soft-tissue sarcoma) or bone (osteosarcoma) $(1,2)$. STS is a diverse group of tumors comprising over 50 subtypes, the most common of which are liposarcoma, derived from adipose tissue, and leiomyosarcoma, derived from smooth muscle. Certain subtypes are primarily pediatric, such as Ewing's sarcoma/primitive neuroectodermal tumors (PNET) and rhabdomyosarcoma (2); others are more common in

Correspondence to: ${ }^{5}$ Present address: Dr Beverly A. Teicher, Developmental Therapeutics Program, National Cancer Institute, 6130 Executive Boulevard, Rockville, MD 20852, USA

E-mail: beverly.teicher@nih.gov

E-mail: teicherba@mail.nih.gov

Key words: endosialin, sarcoma, histologic grade, age, gender adults over 55 years of age, such as leiomyosarcoma, malignant fibrous histiocytoma, synovial sarcoma and liposarcoma. Overall, most STS patients are adults $(3,5)$. Osteosarcoma is primarily pediatric (4).

Surgery with or without adjuvant or neoadjuvant radiation is the most common treatment for localized disease $(2,4)$. Over half of sarcoma patients develop metastatic disease which is treated with chemotherapy. Doxorubicin and ifosfamide are the two most active agents in advanced STS with an average response rate of $20 \%(2,6,7)$. Active agents in pediatric sarcoma are vincristine, doxorubicin, actinomycin D, cyclophosphamide, ifosfamide and etoposide (2). The most active chemotherapeutic agent for osteosarcoma is high-dose methotrexate followed by cisplatin, doxorubicin and ifosfamide (4).

The rare incidence of each sarcoma subtype has made clinical trials challenging. Trials traditionally enroll patients with any sarcoma subtype, despite diverse epidemiologies, pathogeneses, etiologies and clinical manifestations, resulting in highly heterogeneous patient cohorts (6-8). New molecular markers and therapeutics are needed in sarcoma so that therapy can be tailored not only to particular subtypes of sarcoma but to individual patients. The promise of molecular personalized medicine is beginning to be realized in sarcoma with the success of imatinib mesylate and sunitinib in gastrointestinal stromal tumors (GIST) (9).

Several molecular markers known in sarcoma are chromosomal alterations that define certain subtypes. For example, $90 \%$ of alveolar soft-part sarcomas display the $\operatorname{der}(17) \mathrm{t}(\mathrm{X} ; 17)$ (p11;q25) chromosomal alteration involving the ASPL-TFE3 gene, $90 \%$ of desmoplastic small round cell tumors display the $\mathrm{t}(11 ; 22)(\mathrm{p} 13 ; \mathrm{q} 12)$ chromosomal alteration involving EWS-WT1, 90\% of synovial sarcomas display the $\mathrm{t}(\mathrm{X} ; 18)$ (p11;q11) chromosomal alteration involving SYT-SSX1 and SYT-SSX2, and $85 \%$ of Ewing's sarcomas have the $t(11 ; 22)$ (q24;q12) chromosomal alteration involving EWS-FLI1 $(2,3)$. These alterations often involve transcription factors that have a role in disease; however, their exploitation for therapy is challenging (10). Recently, therapeutics targeting growth factor receptors such as IGFR, EGFR, PDGFR-A, PDGFR-B and FLT1, and signaling molecules such as Wnt, AKT/mTOR, 
PI3-K/AKT and MEK/MAPK and JAK1 have shown preclinical promise in sarcoma $(3,11-15)$.

Since the molecular profile of tumors evolves through the course of disease, it is paramount that therapy targets molecules that are expressed in progressing and advanced disease (16-18). In sarcoma, molecular marker and therapeutic target discovery must focus on molecules expressed in patients with poor prognosis or advanced disease. In two separate large-cohort sarcoma studies, histologic grade emerged as an important prognostic factor and as an independent predictor of metastasis. In a study of $>1,000$ adult STS patients, researchers at Memorial Sloan Kettering Cancer Center reported that approximately two thirds of patients had high-grade lesions at presentation. High grade emerged as a key adverse prognostic factor. Patients who presented with high-grade disease had a 5-year distant recurrence-free survival of $63.3 \%$ versus $93 \%$ for those who presented with low-grade disease. Patients who presented with high-grade disease had a median postmetastasis survival of 14 months versus 22.6 for those who presented with low-grade disease (19). In another study of $>1,200$ adult STS patients conducted by the French Federation of Cancer Centers Sarcoma Group, $46 \%$ of patients presented with high-grade disease, and histologic grade emerged as an independent predictor of metastasis. High-grade disease was associated with significantly lower metastasis-free survival in malignant histiocytoma, liposarcoma, leiomyosarcoma, synovial sarcoma, or unclassified sarcomas (20).

From these studies, between one half and two-thirds of sarcoma patients present with high-grade disease and therefore with poor prognosis $(19,20)$. In addition, a number of sarcoma patients have metastatic disease at presentation. Two separate large-cohort studies showed that $8 \%$ of patients with STS present with metastatic disease, the most common site being lung (20-23). Given the high percentage of patients with high-grade or advanced disease at presentation and the poor response rates to conventional therapies, we need to identify molecular markers and therapeutic targets in high-grade and metastatic sarcoma.

Endosialin/CD248/TEM1 recently emerged as a molecular marker and therapeutic target for sarcoma. First recognized as the antigen of an antibody raised in mice against human fetal fibroblasts (FB5), endosialin was found to be expressed by human solid tumor vasculature (24). Endosialin was detected in a subset of colorectal tumor cells enriched for endothelium via selection with P1H12/anti-CD146 (25). Investigations focused on endosialin expression in solid tumor vasculature found that it is expressed mainly in pericytes and stromal fibroblasts (26-32).

The earliest indication that endosialin maybe expressed by malignant cells was the original 1992 report which reported immunoreactivity of FB5 in several neuroblastoma cell lines and mentioned $\mathrm{FB}^{+}$malignant cells in a subset of sarcomas (24). Compelling evidence for endosialin expression by tumor cells came in 2005 with immunostaining of malignant fibrous histiocytoma and liposarcoma showing tumor cell immunoreactivity (33).

Our group conducted a survey of endosialin expression in 86 paraffin-embedded clinical specimens of sarcoma. Immunoreactive tissue components in sarcomas were malignant cells, stromal cells and vasculature. Seventy $(81 \%)$ were positive for endosialin, with $44(51 \%)$ reaching at least $50 \%$ coverage of immunoreactive tissue components. Staining intensity was scored on the scale $0,1+, 2+, 3+$. All 9 sarcoma subtypes included specimens with at least $50 \%$ immunoreactive tissue components positive with a minimum of $2+$ staining intensity indicating the high prevalence of endosialin in sarcomas (34).

Through a retrospective analysis of the diagnostic reports for these specimens, the present study shows that endosialin can be detected in high-grade disease and metastasis. In disseminated human sarcoma xenografts, endosialin was maintained at different anatomic sites including lung. Thus, endosialin is a suitable therapeutic target for poor prognosis and advanced sarcoma.

\section{Materials and methods}

Tissue source. Human clinical sarcoma specimens were obtained from Genzyme Genetics, Analytical Services (Los Angeles, CA). All specimens were collected between 2000 and 2005.

Cells. Human sarcoma cell lines were obtained from the American Type Culture Collection (ATCC, Manassas, VA) except for RMS-YM, MG-63, Hu-O-3N1, HS-OS-1, HS-SY-II, HS-ES-2M, HS-ES-2R, HS-ES-1, HuO-9N2 and 143B/TK^(-) neo $^{\wedge}(\mathrm{R})$ which were obtained from the Riken Bioresource Center (Ibaraki, Japan). All cells were propagated in RPMI medium supplemented with $10 \%$ heat-inactivated fetal bovine serum (FBS) (Invitrogen, Carlsbad, CA).

Immunohistochemistry. The anti-endosialin antibody was generated through a partnership with Kyowa Hakko Kirin Co., Ltd., Takasaki, Japan as described previously (34). Formalinfixed, paraffin-embedded samples were deparaffinized with 3 changes of xylene, rehydrated in baths of 95 and $100 \%$ graded ethanols and rinsed well in running distilled water. Slides were then placed in a pressurized decloaking chamber and pretreated to $125^{\circ} \mathrm{C}$ for $30 \mathrm{sec}$ in sodium citrate epitope retrieval solution (Invitrogen) before cooling down for $15 \mathrm{~min}$ to $95^{\circ} \mathrm{C}$ (slides are in the chamber for a total of $30 \mathrm{~min}$ ). The decloaking chamber was opened and the slides were cooled to room temperature (rt) for $15 \mathrm{~min}$ before being removed and then washed in 3 sequential baths of tris buffered saline/ $0.1 \%$ Tween-20 wash buffer (TBST) for $3 \mathrm{~min}$. All subsequent washes were performed in this manner. Slides were incubated with ready-to-use peroxidase blocking reagent (Dako, Carpinteria, CA) for $5 \mathrm{~min}$ at $\mathrm{rt}$ followed by TBST washes. Slides were then incubated with primary anti-endosialin antibody $(10 \mu \mathrm{g} / \mathrm{ml})$ diluted in antibody diluent (Dako) for $60 \mathrm{~min}$ followed by TBST washes. The slides were then incubated with a Vectastain Elite ABC detection reagent (Vector Laboratories, Burlingame, CA) diluted in TBST at 1:50 for $30 \mathrm{~min}$ at $\mathrm{rt}$ followed by TBST washes. Peroxidase reaction was visualized by incubating with a 3,3'-diaminobenzidine tetrahydrochloride (DAB) solution (Dako) for $5 \mathrm{~min}$ at $\mathrm{rt}$ and then washed in distilled water for $1 \mathrm{~min}$. The slides were then re-rinsed with distilled water 3 times for 30-60 sec each, counterstained with Dako hematoxylin for $2 \mathrm{~min}$, washed in TBST, dehydrated through graded alcohols, cleared in xylene and coverslipped. Endosialin staining was scored independently by two pathologists. Immunoreactive 
tissue components were vasculature, stromal cells and/or tumor cells. Staining intensity was scored on the scale $0,1+$, $2+$ and $3+$. Since tumors were heterogeneous, the percentage of immunoreactive tissue components staining at each intensity level was recorded. That percentage refers to all three immunoreactive tissue components (vasculature, stromal cells and tumor cells) as a whole. The Long H-score is a single summary value encompassing staining intensity and percent staining coverage. The Long $\mathrm{H}$-score was calculated for each specimen by multiplying each staining intensity $(0,1,2$ or $3+)$ by the corresponding percent tissue coverage and adding the values. Long $\mathrm{H}$-scores range from 0 to 300 .

Statistical analysis of human clinical specimen diagnostic reports. JMP software (SAS Institute, Inc., Cary, NC) was used to conduct a linear regression analysis to uncover any linear relationship between endosialin level and the endosialin cell type expression pattern, sarcoma subtype, disease grade, patient age and patient gender. Three measurements of endosialin levels were derived from the IHC scores of clinical specimens: Long H-score (Y), percent staining coverage $\geq 1+$ staining intensity (Y1), percent staining coverage $\geq 2+$ staining intensity (Y2) and percent staining coverage at $3+$ staining intensity (Y3). Y was a continuous variable ranging from 0 to 300 and $\mathrm{Y} 1, \mathrm{Y} 2$ and $\mathrm{Y} 3$ were continuous variables ranging from 0 to 100. The linear regression analysis was used to identify relationships between each of Y, Y1, Y2 and Y3 and the following other variables: endosialin cell type expression pattern, sarcoma subtype, disease grade, patient age and patient gender. The cell type expression pattern variable arose from the observation that endosialin could be detected in vascular and/or stromal cells in some clinical specimens, and in tumor cells (with or without additional expression in vascular and/or stromal cells) in others. We wondered whether specimens with endosialinpositive tumor cells might have overall higher levels of endosialin expression compared to specimens with no tumor cell staining and only vascular and/or stromal staining. We identified three main endosialin cell type expression patterns: no endosialin expression (score, 0 ), endosialin expression in vascular cells and/or stromal cells (score, 1) and endosialin expression in tumor cells alone or in tumor cells in addition to vascular and/ or stromal cells (score, 2). The sarcoma subtype variable encompassed the nine subtypes represented in our IHC survey of clinical specimens: angiosarcoma (T1), Ewing's sarcoma (T2), fibrosarcoma (T3), GIST (T4), liposarcoma (T5), malignant fibrous histiocytoma (T6), osteosarcoma (T7), rhabdomyosarcoma (T8) and synovial sarcoma (T9). The disease grade variable $(\mathrm{G})$ was low grade (score, 0 ) or high grade (score, 1). Age (A) was a continuous variable ranging from 0 to 97 years. The gender variable (M) was female (score, 0) or male (score, 1). A linear regression was used to fit the data and a stepwise selection method was applied to identify significant variables and interactions. Relationships with $\mathrm{P}<0.05$ were considered significant (both entry level and stay level were set as 0.05).

Flow cytometry. Analysis of endosialin expression in live cells by flow cytometry was conducted as previously described using a fully human monoclonal antibody raised against human endosialin and a fully human isotype control antibody raised against dinitrophenol (DNP) (34). Sample acquisition was conducted on a FACSCalibur instrument (Becton-Dickinson Labware, Franklin Lakes, NJ) and analysis with Flow Jo (Tree Star Inc., Ashland, OR).

RNA isolation and real-time PCR analysis. RNA isolation and analysis, cDNA synthesis and real-time PCR were conducted as described previously (34).

In vivo sarcoma xenografts. All procedures were carried out according to a protocol approved by the Institutional Animal Care and Use Committee in accordance with the Federal Animal Welfare Act (9 CFR, 1992) and conducted in an AAALAC accredited facility. For subcutaneous models, A-673 Ewing's sarcoma, SJSA-1 osteosarcoma and MES-SA uterine sarcoma cells grown in culture were implanted subcutaneously $\left(1 \times 10^{6}\right)$ in the flanks of nude mice (Harlan Laboratories, Inc., Indianapolis, IN) and passaged 4-times from mouse to mouse using trocar implants. Animals were sacrificed and tumors excised when tumor size reached $400 \mathrm{~mm}^{3}$. For disseminated models, cells grown in culture were delivered IV $\left(1 \times 10^{6}\right)$ into the tail vein of $\mathrm{CB} 17 / \mathrm{ICrCrl}-\mathrm{scid}-\mathrm{bgBR}$ mice (Charles River, Wilmington, MA) in a $200 \mu \mathrm{l}$ volume in PBS. SJSA-1 osteosarcoma cells were injected into male mice and A-673 Ewing's sarcoma cells and MES-SA uterine sarcoma cells were injected into female mice, according to the gender of the cells. Each cell line was injected into four mice. Animals were euthanized by $\mathrm{CO}_{2}$ asphyxiation when weight loss reached $10 \%$ of body weight or when experiencing any sign of pain or distress. Tumors and organs were collected and fixed in formalin for IHC analysis.

Microcomputerized tomography (micro-CT). Micro-CT was performed post mortem on mice bearing disseminated A-673 tumors (GE eXplore Locus, London, Ontario, Canada). The instrument was calibrated to established standards, and fitted with a mouse bed. The study mice were euthanized according to facility guidelines, and positioned feet first/prone on the scan bed. The imaging was performed with a voxel size of $0.0414 \wedge 3,40 \times 40 \times 40 \mathrm{~mm}$ (cube) scan range, 256x256 pixel FOV; power settings of $450 \mu \mathrm{A}$ and $80 \mathrm{kV}$. The resulting data were reconstructed and an isosurface generated with a $800 \mathrm{HU}$ threshold.

\section{Results}

Retrospective analysis of clinical specimen diagnostic reports. Diagnostic reports for 83 human clinical sarcoma specimens among those that had previously been stained for endosialin by IHC were assessed (Fig. 1) (34). The reports indicated sarcoma subtype, disease grade, tumor anatomic location, patient gender and patient age. Not all reports included all of these data-points. Grade was available for 69/83 clinical specimens. Age was available for 82 specimens and ranged from 3 to 97 years. Gender was available for all 83 specimens, 39 were from female patients and 44 from male patients.

Our first goal was to determine whether endosialin was expressed in advanced disease. Three of the 83 specimens were metastatic lesions, as evidenced by resection from lymph nodes: angiosarcoma P101, rhabdomyosarcoma P167 
A

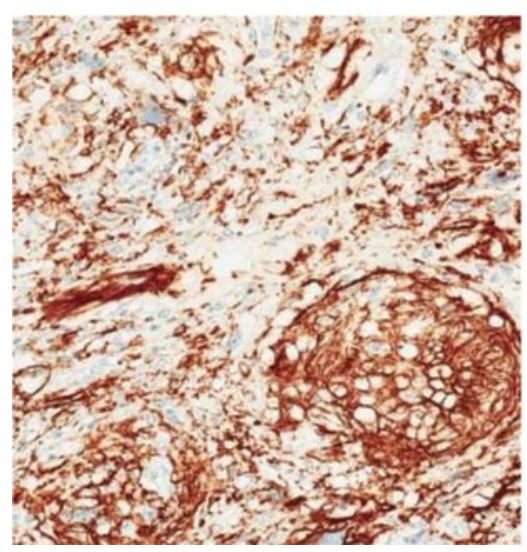

D
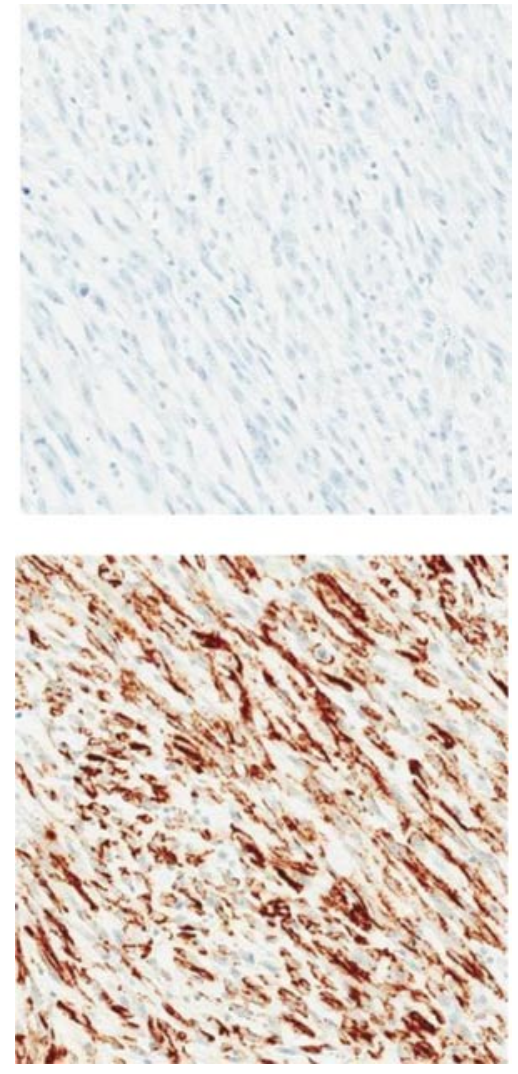

B
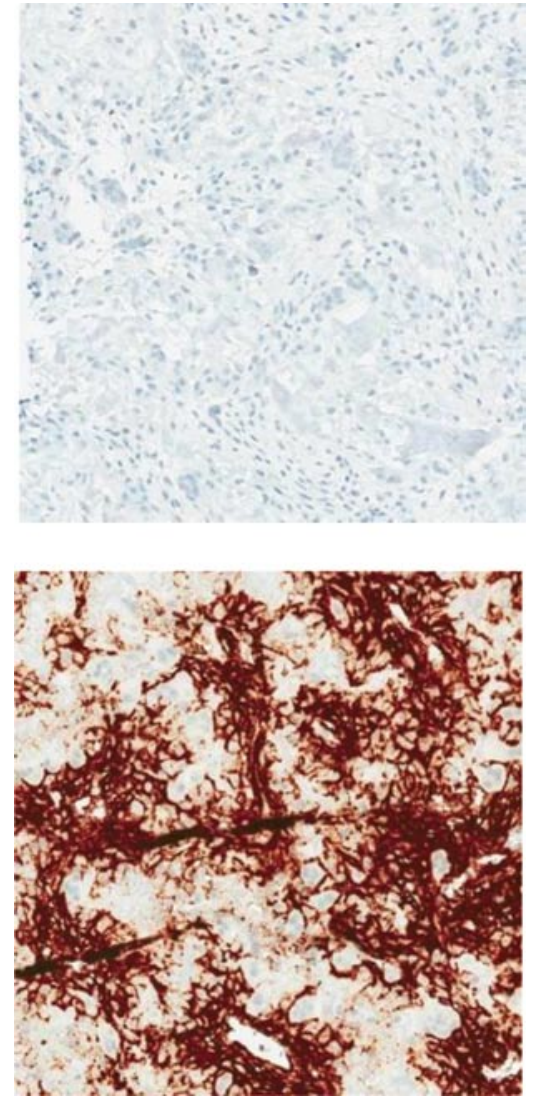

$\mathbf{E}$
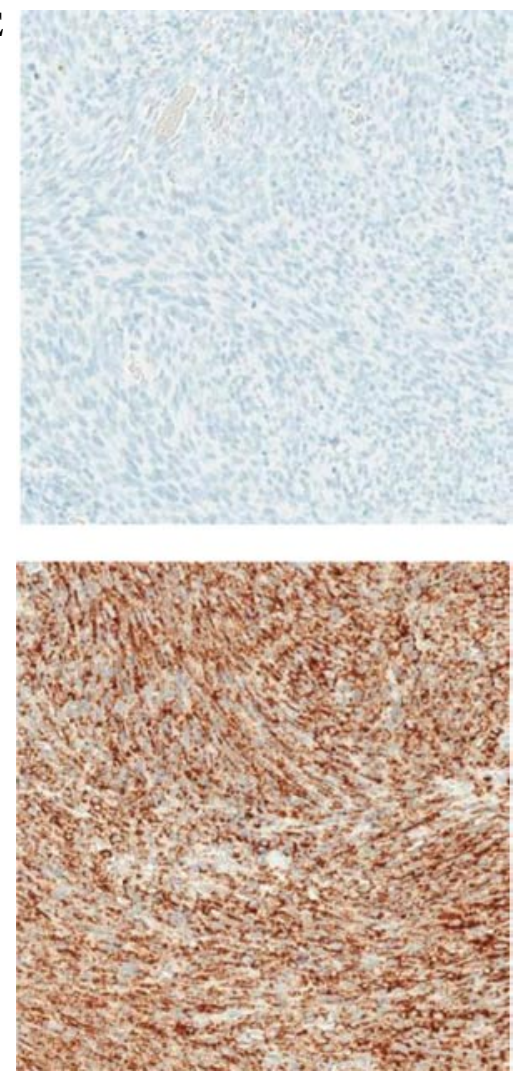

C
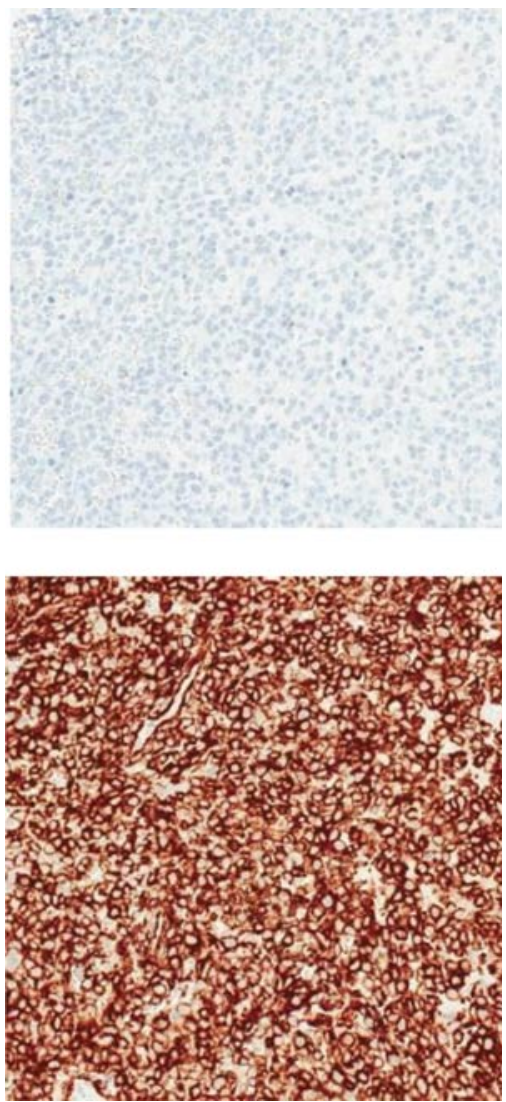

Figure 1. Expression of endosialin by immunohistochemistry in human clinical specimens of sarcoma. Liposarcoma FFPE139 (A), osteosarcoma FFPE-162 (B). Ewing's sarcoma FFPE-114 (C), fibrosarcoma FFPE-121 (D). Synovial sarcoma FFPE178 (E). Bottom, anti-endosialin; top, isotype control. $20 \mathrm{X}$ objective.

and rhabdomyosarcoma P173 (Table I). Similarly Ewing's sarcomas P108 and P113, resected from scalp, were metastases since the site of origin of Ewing's sarcoma is primarily bone
(Table I) (35). GIST P128 was also a metastasis since the abdominal wall is not a typical site of origin for GIST which arises in the gastrointestinal tract, primarily in the stomach 
Table I. Human clinical specimen diagnostic report information.

\begin{tabular}{|c|c|c|c|c|c|}
\hline Patient ID & Sarcoma subtype & Body site & Grade level & Age & Gender \\
\hline FFPE-P101 & Angiosarcoma & Hilar lymph node & High grade & 17 & M \\
\hline FFPE-P102 & Angiosarcoma & Pericardium & High grade & 54 & M \\
\hline FFPE-P103 & Angiosarcoma & Rt tibia & High grade & 67 & M \\
\hline FFPE-P104 & Angiosarcoma & Scalp & & 75 & M \\
\hline FFPE-P105 & Angiosarcoma & Lt femur & High grade & 77 & $\mathrm{~F}$ \\
\hline FFPE-P106 & Angiosarcoma & Lt chest wall & High grade & 82 & $\mathrm{~F}$ \\
\hline FFPE-P108 & Ewing's sarcoma & Scalp & & 10 & M \\
\hline FFPE-P109 & Ewing's sarcoma & Rt thigh & High grade & 12 & M \\
\hline FFPE-P110 & Ewing's sarcoma & Humerus & High grade & 31 & $\mathrm{~F}$ \\
\hline FFPE-P111 & Ewing's sarcoma & Chest & & 56 & M \\
\hline FFPE-P112 & Ewing's sarcoma & Brain & & 29 & $\mathrm{~F}$ \\
\hline FFPE-P113 & Ewing's sarcoma & Scalp & & 10 & M \\
\hline FFPE-P114 & Ewing's sarcoma & Rt labia majora & High grade & 9 & $\mathrm{~F}$ \\
\hline FFPE-P115 & Ewing's sarcoma & Lt leg & High grade & 3 & M \\
\hline FFPE-P116 & Ewing's sarcoma & Humerus & High grade & 20 & M \\
\hline FFPE-P117 & Fibrosarcoma & Soft tissues & & 97 & $\mathrm{~F}$ \\
\hline FFPE-P118 & Fibrosarcoma & Scalp & High grade & 49 & $\mathrm{~F}$ \\
\hline FFPE-P119 & Fibrosarcoma & Cecum & & 64 & $\mathrm{~F}$ \\
\hline FFPE-P120 & Fibrosarcoma & Lt ankle & & 62 & $\mathrm{~F}$ \\
\hline FFPE-P121 & Fibrosarcoma & Penis & High grade & 81 & M \\
\hline FFPE-P122 & Fibrosarcoma & Lt thigh & High grade & 50 & M \\
\hline FFPE-P123 & Fibrosarcoma & Scalp & High grade & 76 & $\mathrm{~F}$ \\
\hline FFPE-P125 & GIST & Abdomen & Low grade & 78 & $\mathrm{~F}$ \\
\hline FFPE-P126 & GIST & Gastric & & 46 & M \\
\hline FFPE-P127 & GIST & Small bowel & Low grade & 51 & $\mathrm{~F}$ \\
\hline FFPE-P128 & GIST & Abdominal wall & High grade & 82 & $\mathrm{~F}$ \\
\hline FFPE-P129 & GIST & Gastric & Low grade & 44 & M \\
\hline FFPE-P130 & GIST & Stomach & Low grade & 81 & M \\
\hline FFPE-P131 & GIST & Gastric & Low grade & 72 & M \\
\hline FFPE-P132 & GIST & Stomach & & 55 & $\mathrm{~F}$ \\
\hline FFPE-P133 & GIST & Gastric & Low grade & 52 & M \\
\hline FFPE-P134 & GIST & Stomach & Low grade & 48 & M \\
\hline FFPE-P135 & Liposarcoma & Rt flank & & 60 & M \\
\hline FFPE-P136 & Liposarcoma & Rt thigh & High grade & 75 & $\mathrm{~F}$ \\
\hline FFPE-P137 & Liposarcoma & Mesentery & & 85 & $\mathrm{~F}$ \\
\hline FFPE-P138 & Liposarcoma & Lt chest wall & High grade & 42 & $\mathrm{~F}$ \\
\hline FFPE-P139 & Liposarcoma & Abdominal wall & Low grade & 68 & $\mathrm{~F}$ \\
\hline FFPE-P140 & Liposarcoma & Rt thigh & Low grade & 55 & $\mathrm{~F}$ \\
\hline FFPE-P141 & Liposarcoma & Lt thigh & High grade & 42 & M \\
\hline FFPE-P142 & Liposarcoma & Lung & High grade & 63 & $\mathrm{~F}$ \\
\hline FFPE-P143 & Liposarcoma & Pararenal mass & High grade & 73 & $\mathrm{~F}$ \\
\hline FFPE-P144 & Liposarcoma & Anterior mediastinum & High grade & 81 & M \\
\hline FFPE-P145 & MFH & Lt thigh & High grade & 76 & $\mathrm{~F}$ \\
\hline FFPE-P146 & MFH & Lt humerus & High grade & 65 & M \\
\hline FFPE-P147 & MFH & Lt buttock & High grade & 50 & M \\
\hline FFPE-P148 & MFH & Lt back & High grade & 83 & M \\
\hline FFPE-P149 & MFH & Lt thigh & & $?$ & $\mathrm{~F}$ \\
\hline FFPE-P150 & MFH & Forehead, Rt & & 83 & M \\
\hline FFPE-P151 & MFH & Knee & & 74 & M \\
\hline FFPE-P152 & MFH & Thigh & High grade & 78 & M \\
\hline FFPE-P153 & $\mathrm{MFH}$ & Rt thigh & High grade & 44 & M \\
\hline FFPE-P154 & $\mathrm{MFH}$ & Lt breast & High grade & 55 & $\mathrm{~F}$ \\
\hline
\end{tabular}


Table I. Continued.

\begin{tabular}{|c|c|c|c|c|c|}
\hline Patient ID & Sarcoma subtype & Body site & Grade level & Age & Gender \\
\hline FFPE-P155 & MFH & Retroperitoneum & High grade & 55 & M \\
\hline FFPE-P156 & Osteosarcoma & Rt leg & High grade & 83 & M \\
\hline FFPE-P157 & Osteosarcoma & Rt femur & & 57 & M \\
\hline FFPE-P158 & Osteosarcoma & Rt maxilla & & 27 & $\mathrm{~F}$ \\
\hline FFPE-P159 & Osteosarcoma & Lt breast & High grade & 85 & $\mathrm{~F}$ \\
\hline FFPE-P160 & Osteosarcoma & Rt thigh & High grade & 60 & M \\
\hline FFPE-P161 & Osteosarcoma & Rt ear & & 57 & M \\
\hline FFPE-P162 & Osteosarcoma & Rt breast & High grade & 61 & $\mathrm{~F}$ \\
\hline FFPE-P163 & Osteosarcoma & Rt arm & & 42 & $\mathrm{~F}$ \\
\hline FFPE-P164 & Osteosarcoma & Rt femur & High grade & 20 & $\mathrm{~F}$ \\
\hline FFPE-P165 & Osteosarcoma & Rt maxilla & High grade & 27 & $\mathrm{~F}$ \\
\hline FFPE-P167 & Rhabdomyosarcoma & Lt inguinal node & High grade & 10 & $\mathrm{~F}$ \\
\hline FFPE-P168 & Rhabdomyosarcoma & Rt testis & & 17 & M \\
\hline FFPE-P169 & Rhabdomyosarcoma & Vagina & High grade & 15 & $\mathrm{~F}$ \\
\hline FFPE-P170 & Rhabdomyosarcoma & Nasopharynx & High grade & 9 & M \\
\hline FFPE-P171 & Rhabdomyosarcoma & Buccal mucosa & High grade & 34 & $\mathrm{~F}$ \\
\hline FFPE-P172 & Rhabdomyosarcoma & Liver & High grade & 66 & $\mathrm{~F}$ \\
\hline FFPE-P173 & Rhabdomyosarcoma & Cervical lymph node & High grade & 17 & $\mathrm{~F}$ \\
\hline FFPE-P174 & Rhabdomyosarcoma & Right testis & & 17 & M \\
\hline FFPE-P175 & Rhabdomyosarcoma & Paraspinal & High grade & 17 & $\mathrm{~F}$ \\
\hline FFPE-P176 & Rhabdomyosarcoma & Thoracic spine & High grade & 29 & M \\
\hline FFPE-P177 & Synovial sarcoma & Heart & High grade & 23 & M \\
\hline FFPE-P178 & Synovial sarcoma & Lt thigh & High grade & 19 & $\mathrm{~F}$ \\
\hline FFPE-P179 & Synovial sarcoma & Esophagogastric junction & High grade & 59 & $\mathrm{~F}$ \\
\hline FFPE-P180 & Synovial sarcoma & Rt thigh & High grade & 56 & M \\
\hline FFPE-P181 & Synovial sarcoma & Back & High grade & 32 & M \\
\hline FFPE-P182 & Synovial sarcoma & Rt thigh & High grade & 25 & $\mathrm{~F}$ \\
\hline FFPE-P183 & Synovial sarcoma & Rt proximal leg & & 43 & M \\
\hline FFPE-P184 & Synovial Sarcoma & Back & High grade & 58 & M \\
\hline FFPE-P185 & Synovial sarcoma & Lt forearm & High grade & 21 & M \\
\hline FFPE-P186 & Synovial Sarcoma & Rt upper lobe lung & High grade & 81 & M \\
\hline
\end{tabular}

and small intestine, and gives rise to intra-abdominal metastases and liver metastases (Table I) (36). Five of the 6 metastases (angiosarcoma P101, rhabdomyosarcoma P167, rhabdomyosarcoma P173, Ewing's sarcoma P113 and GIST P128) were positive for endosialin with respective Long $\mathrm{H}$-scores of 70 , 215, 150, 75 and 115. One of 5 endosialin-positive metastases, Ewing's sarcoma P113, showed positivity in tumor cells and vascular cells. These clinical specimens demonstrate that endosialin can be detected in advanced disease.

Seven additional specimens were suspected metastases based upon anatomic locations. Even though a primary brain Ewing's sarcoma has been reported in the literature, Ewing's sarcoma P112 was likely a brain metastasis since brain is a rare primary site for Ewing's sarcoma (37). Similarly, despite reports of rare primary liposarcomas in chest wall, lung and mediastinum, liposarcomas P138, P142 and P144 were likely to be metastases (Table I) (38-44). Since primary MFH can arise in head and neck, in the absence of any additional anatomical annotation it is possible that MFH P150, located on the forehead, was a primary tumor (45). However, the forehead is an unusual primary site for MFH suggesting that specimen P150 was likely a metastasis (Table I). Although primary rhabdomyosarcoma of the liver has been reported, rhabdomyosarcoma P172 was likely a metastatic lesion since liver is an unusual site for primary rhabdomyosarcoma (46-48). Finally, although rare primary synovial sarcomas have been reported in lung, lung remains an unusual primary site for synovial sarcoma and a frequent metastatic site, suggesting that specimen P186 was likely a metastasis (Table I) $(49,50)$. Five of these 7 suspected metastases were positive for endosialin with long H-scores of 35 (Ewing's sarcoma P112), 265 (liposarcoma P138), 60 (liposarcoma P142), 175 (MFH P150) and 65 (rhabdomyosarcoma P172). Three of 7 had endosialin-positive tumor cells (Ewing's sarcoma P112, liposarcoma P138 and MFH P150).

Since high grade is an independent predictor of disease progression in sarcoma, we sought to determine whether endosialin could be detected in high-grade clinical specimens. 


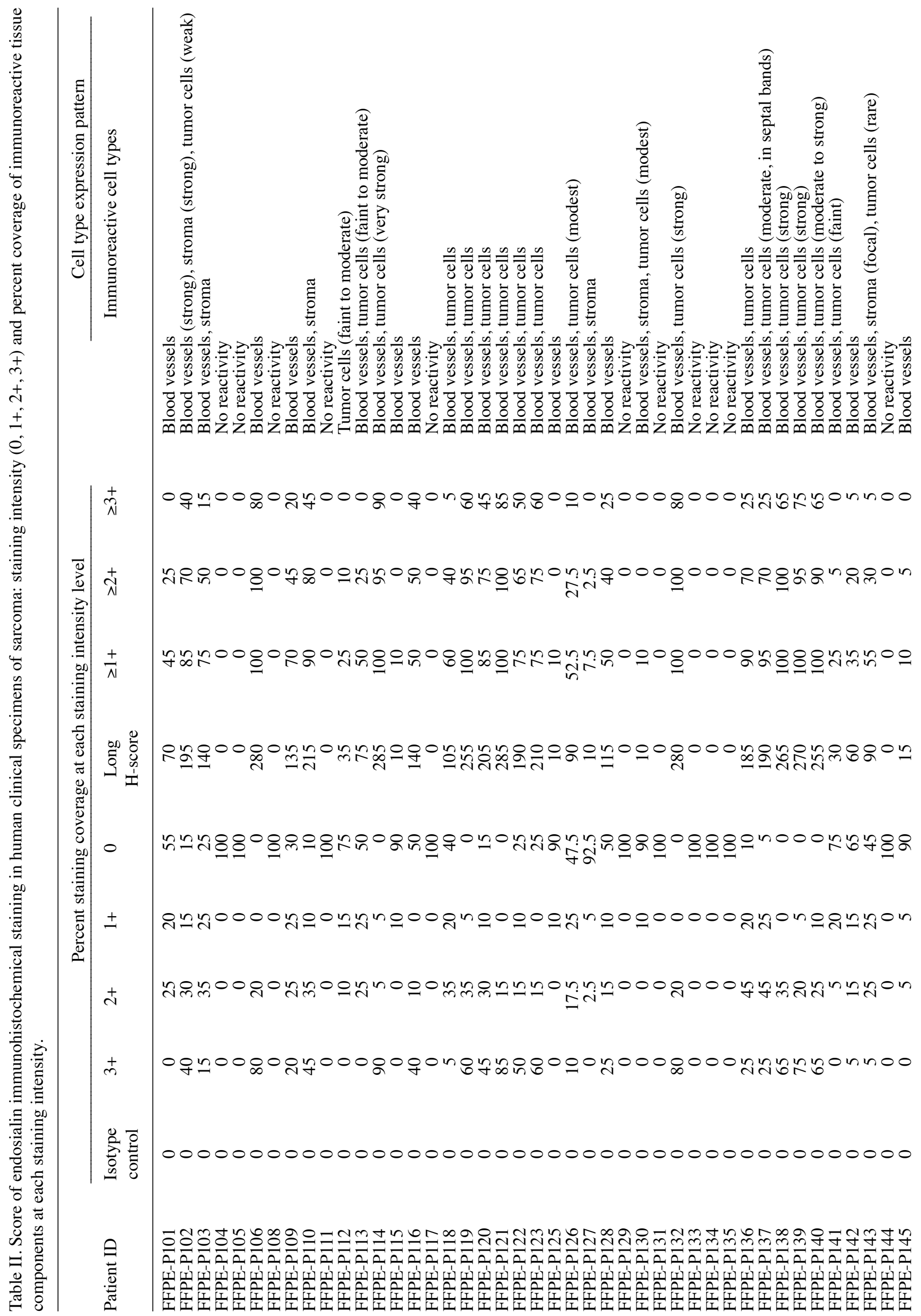




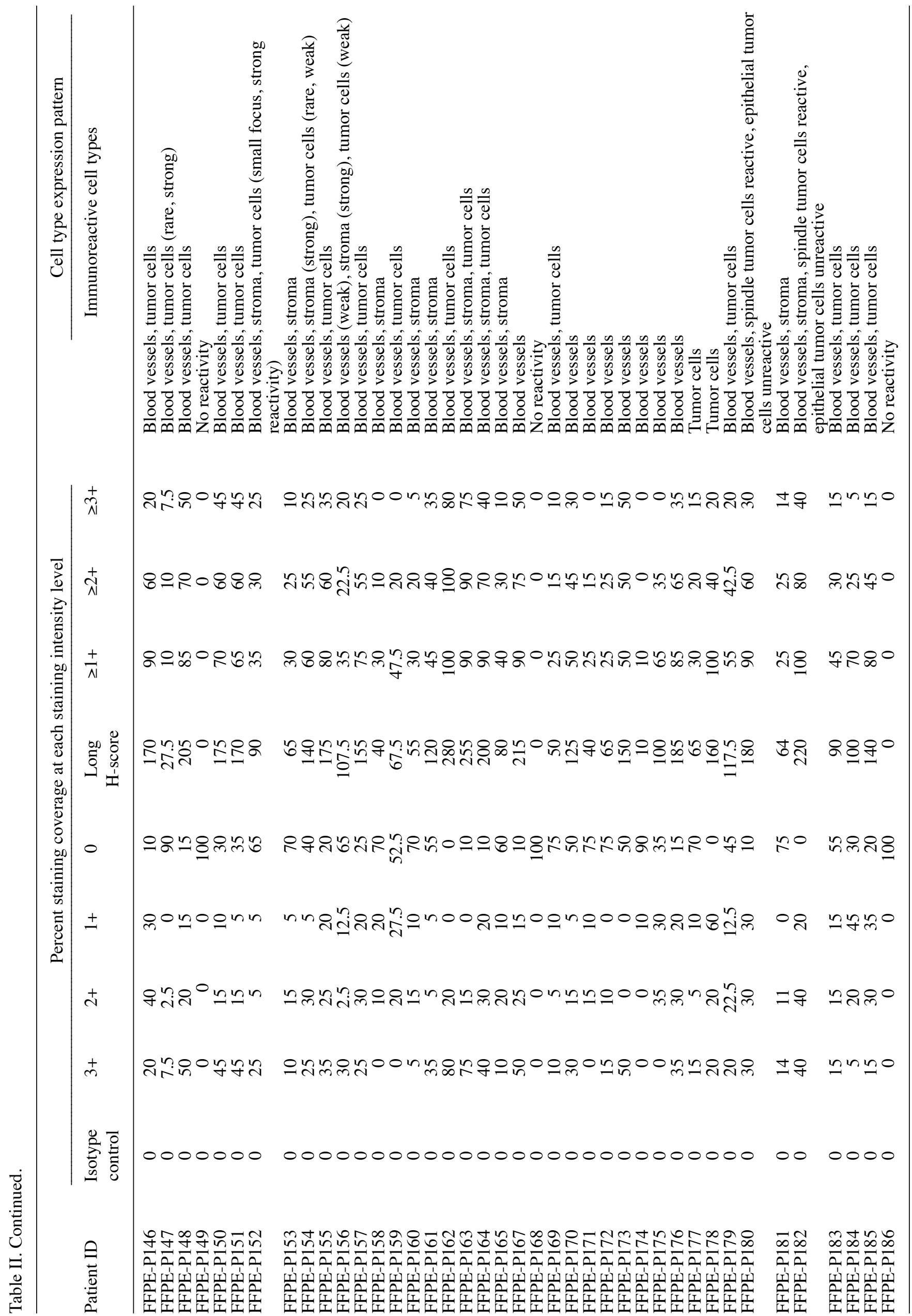


Of 69 diagnostic reports providing grade information, 13 were low grade and 56 were high grade. Seven of 13 low-grade specimens were GIST, 3 were liposarcomas, 2 were fibrosarcomas and 1 was Ewing's sarcoma. Endosialin-positive specimens, including specimens with $100 \%$ of tumor cells staining positive for endosialin, occurred among both the low-grade and highgrade groups, suggesting that endosialin can be expressed throughout the course of the disease (Table I).

Next we determined whether endosialin levels correlated with disease grade and were elevated in high grade compared to low grade. Using the same statistical method, we determined whether endosialin levels correlated with sarcoma subtype, patient age or patient gender. Finally we determined whether endosialin levels were higher in clinical specimens with tumor cell expression compared to those with no tumor cell expression. A linear regression model was used to fit the data (data not shown). For the analysis, the Long H-score (Y), a summary value encompassing the percent staining coverage at each staining intensity $(0,1+, 2+$ and $3+)$, was the preferred measure of endosialin levels. The same analysis was also performed for the percent coverage with $\geq 1+$ staining intensity (Y1), for the percent coverage with $\geq 2+$ staining intensity (Y2) and for the percent coverage with at $3+$ staining intensity (Y3) (Table II). A stepwise selection method was applied to identify significant variables and interactions. Relationships with $\mathrm{P}<0.05$ were considered significant.

The analysis showed that endosialin levels were higher in high-grade than low-grade specimens in all sarcoma subtypes except liposarcoma, where endosialin levels were higher in low-grade specimens. The positive correlation between grade and endosialin level was significant whether endosialin levels were assessed using the Long $\mathrm{H}$-score $(\mathrm{Y})$ or the percent staining coverage at $3+$ intensity levels (Y3). In addition, endosialin levels tended to be higher in specimens with tumor cell staining compared to specimens with only vascular and/or stromal cell staining for all the sarcoma subtypes studied ( $\chi^{2}$ test, $\left.\mathrm{P}<0.0001\right)$. This relationship held whether endosialin levels were assessed using the Long $\mathrm{H}$-score $(\mathrm{Y})$, the percent coverage $\geq 1+$ staining intensity (Y1), the percent coverage $\geq 2+$ staining intensity (Y2) or the percent coverage at $3+$ staining intensity (Y3). There was no relationship between tumor cell expression of endosialin and sarcoma subtype ( $\chi^{2}$ test, $\left.\mathrm{P}=0.1014\right)$ or gender $\left(\chi^{2}\right.$ test, $\mathrm{P}=0.8788$ ) but tumor cell expression of endosialin was a more frequent event in high-grade disease compared to low-grade disease $\left(\chi^{2}\right.$ test, $\left.\mathrm{P}<0.0001\right)$.

Overall endosialin levels were higher in female patients than in male patients only when the percent coverage was $\geq 1+$ staining intensity (Y1) or $\geq 2+$ staining intensity (Y2). When the Long $\mathrm{H}$-score $(\mathrm{Y})$ or the percent coverage at 3+ intensity level (Y3) was used, there was no correlation between endosialin and gender; thus, the association between endosialin level and gender was weak. Finally, endosialin levels did not correlate with age.

In vitro and in vivo modeling. Forty-two human sarcoma cell lines representing a broad range of tissue types, anatomic locations and patient ages were analyzed for endosialin expression (Table III). Twenty-two of 42 cell lines were positive for endosialin and 20 were negative. The 22 positive cell lines were A-673, Hs 822.T and Hs 863.T Ewing's sarcoma, G-401 rhabdoid tumor, Hs 729.T and RMS-YM rhabdomyosarcoma, HOS, HS-OS-1, HuO 9N2 and SJSA-1 osteosarcoma, Hs 132.T spindle cell sarcoma, Hs 414.T and Hs 93.T fibrosarcoma, Hs 737.T and Hs 821.T giant cell sarcoma, and MES-SA, MES-SA/Dx5 and MES-SA/MX2 uterine sarcoma. Four of 22 cell lines positive for endosialin have unclear origin: Hs 57.T is classified as either a sarcoma or lymphoma, SK-ES-1 is classified as either an anaplastic osteosarcoma or a Ewing's sarcoma and we were unable to confirm by chromosome analysis that SW982 was derived from a synovial sarcoma or SW872 from a liposarcoma (35). Although the A-673 cell line was designated a rhabdomyosarcoma, it has been reclassified as Ewing's sarcoma (34). The cell line with the highest expression of endosialin, based on mean fluorescence, was the SJSA-1 osteosarcoma cell line while the MES-SA/Dx5 and MES-SA/ MX2 had the lowest levels of expression (Fig. 2A and Table III). Thirty-one human sarcoma cell lines were analyzed for endosialin mRNA levels by real-time PCR. There was a positive correlation between mRNA and protein levels except for the RD-ES cell line where mRNA was detected in the absence of protein (Fig. 2B).

The A-673 Ewing's sarcoma, SJSA-1 osteosarcoma and MES-SA uterine sarcoma cells were implanted subcutaneously in nude mice (Fig. 3). Immunohistochemical analysis showed that endosialin expression was maintained in the tumors. As in the human clinical specimens, expression was heterogeneous in the xenograft tumor tissue with regions of each tumor having staining intensities from 0 to $3+$ (Fig. 3).

The same tumor cells were injected intravenously to model advanced disseminated disease. In the human A-673 Ewing's sarcoma xenograft group, two mice developed rear limb paralysis on days 30-33. MicroCT imaging post mortem showed bone degradation in the sacral space and microscopic lung metastases upon examination. Upon necropsy, a large ovarian tumor mass was observed in one of the two mice. On day 37, another mouse was removed from the study with a tumor mass encompassing the heart that was consistent with a tracheobronchial lymph node involvement, and a second tumor mass under the right upper limb that was consistent with brachial lymph node involvement. The fourth mouse was removed from study on day 42 post-cell injection with a tumor on the right side of the neck consistent with submandibular lymph node involvement. In the human SJSA-1 osteosarcoma xenograft group, all mice were removed from study due to body weight loss at days 33-37 post cell injection and had large lung tumor burdens. In the human MES-SA uterine sarcoma xenograft group, one mouse was removed from study at day 44 post cell injection with body weight loss. Upon necropsy, a large tumor mass was observed encompassing the adrenal gland. The other three mice in the group were removed from study at day 56 and no tumor was detected upon necropsy.

All A-673 Ewing's sarcoma, SJSA-1 osteosarcoma and MES-SA uterine sarcoma disseminated tumors were positive for endosialin by immunohistochemistry and all reached $3+$ staining intensity (Fig. 4). In the A-673 Ewing's sarcoma model, some nodules showed homogeneous 3+ staining, while other nodules showed staining heterogeneity with intensity ranging from $1+$ to $3+$ (Table II and Fig. 4). In the SJSA-1 osteosarcoma tumor model, subcutaneous tumors and disseminated tumors displayed staining intensity ranging from 


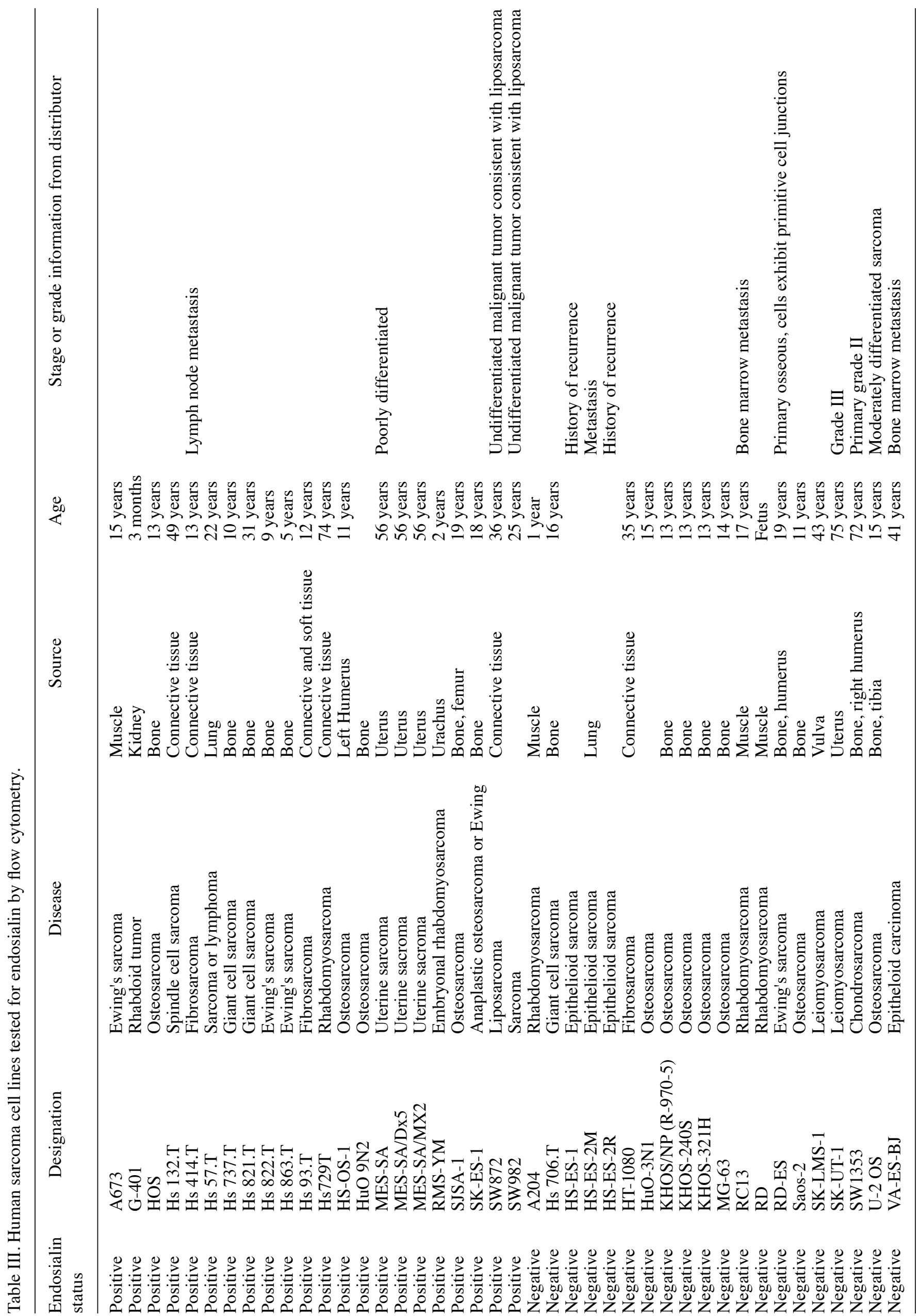


A

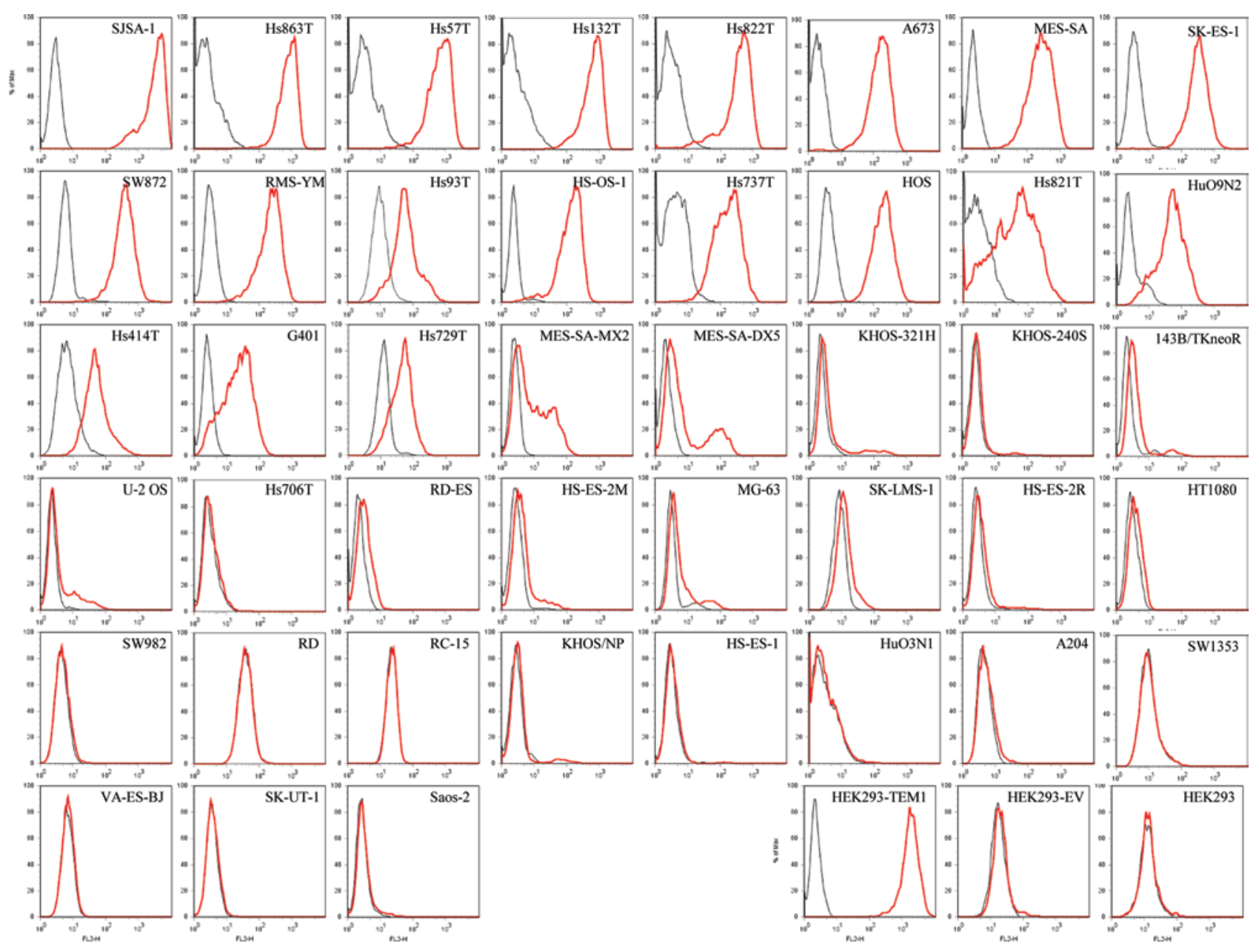

B

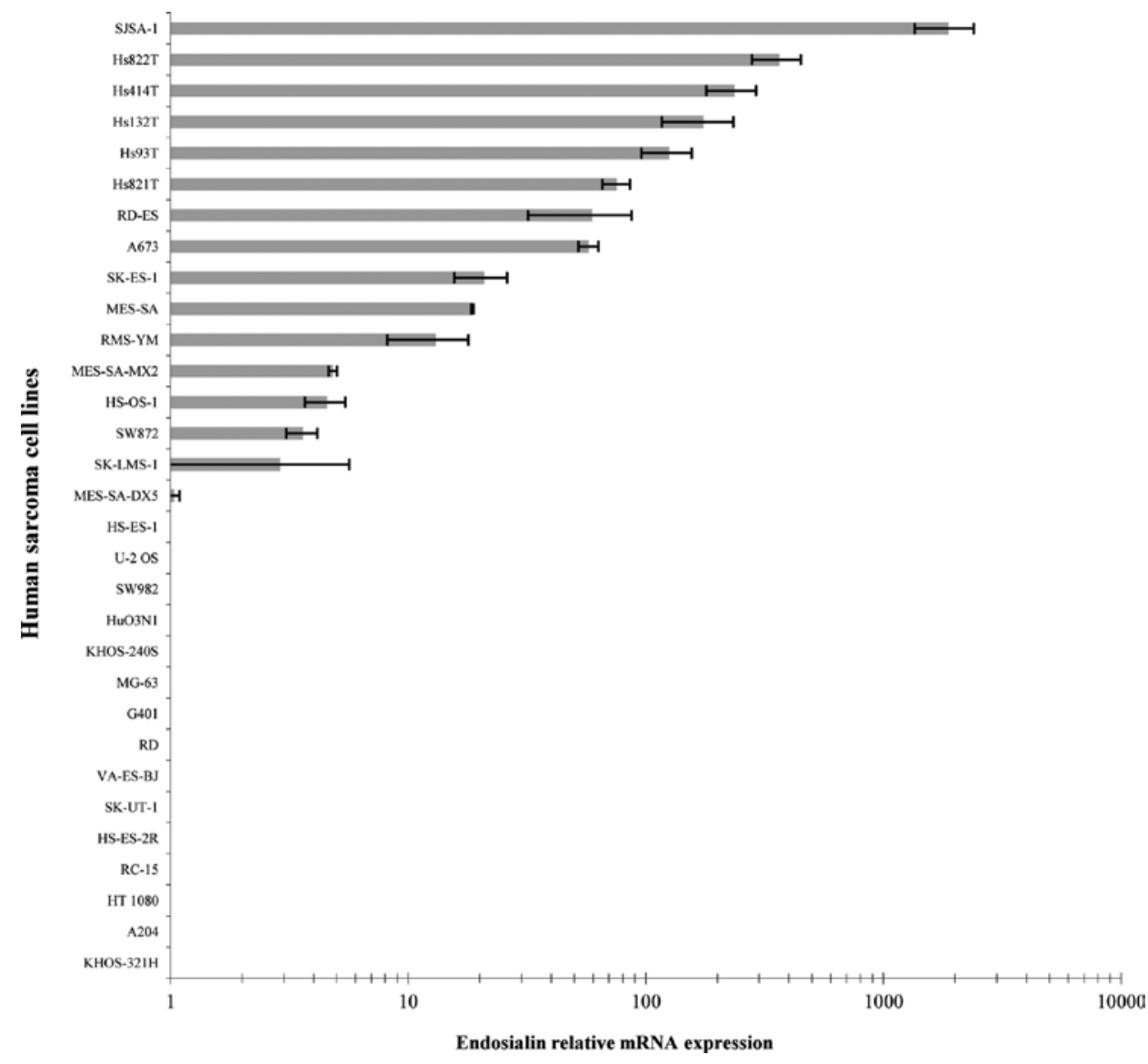

Figure 2. Expression of endosialin in human sarcoma cell lines in vitro by flow cytometry (A) and by real-time PCR (B). 
A
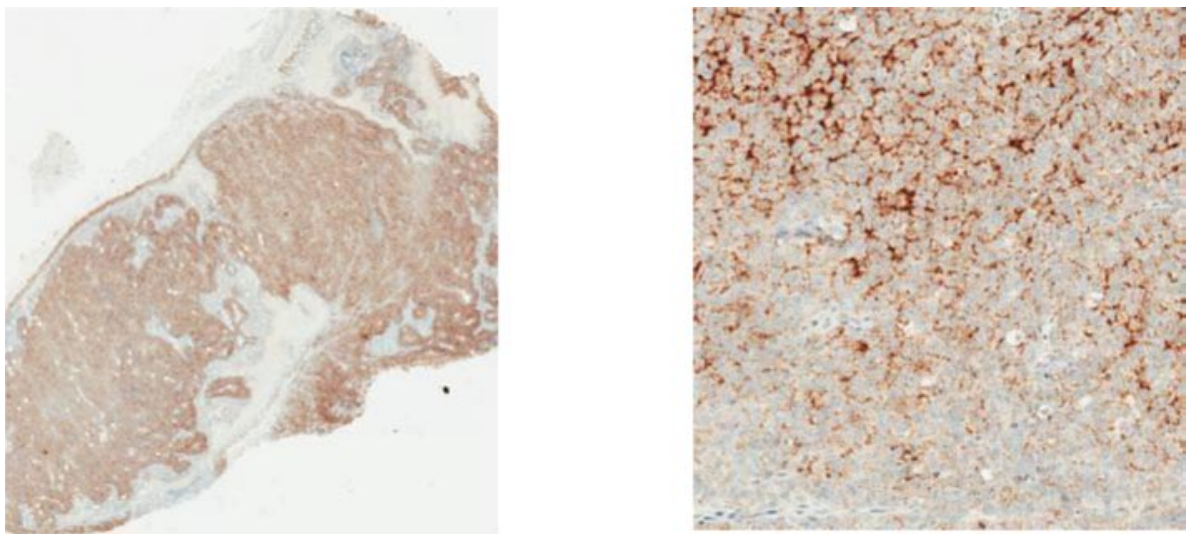

B
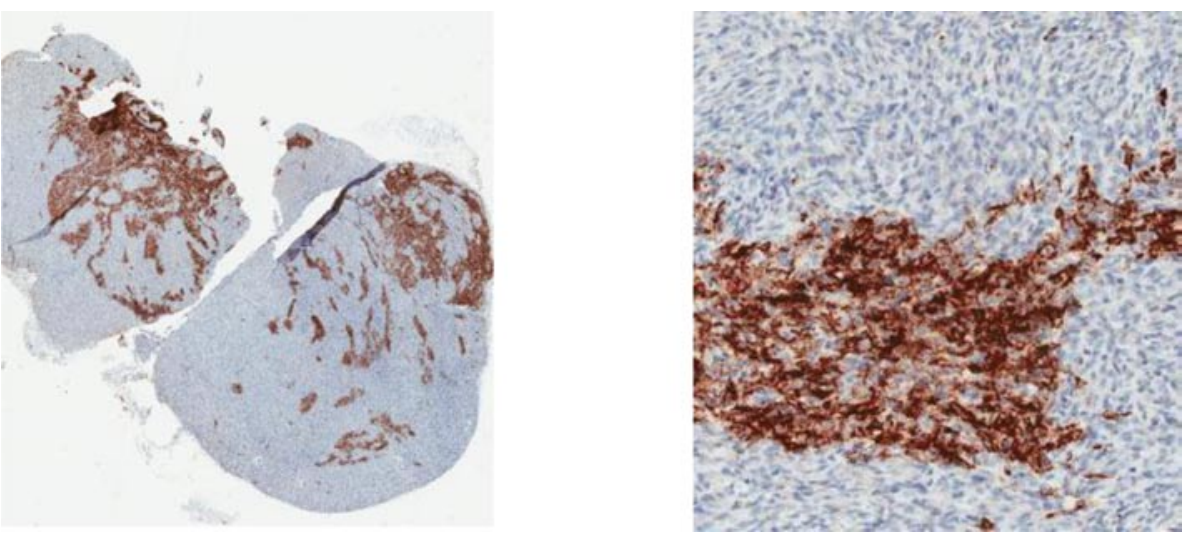

C
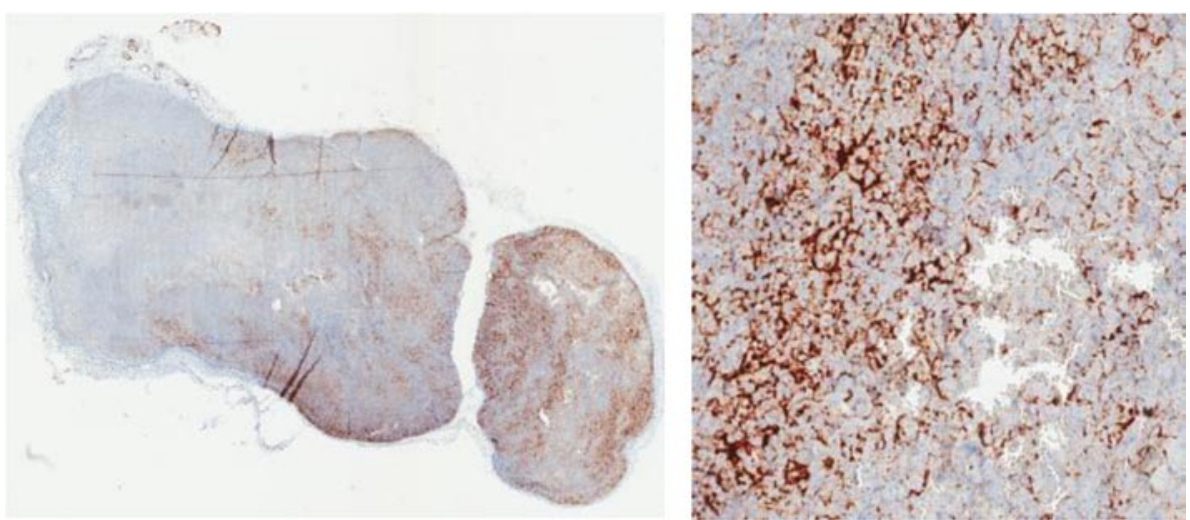

D

\begin{tabular}{|l|c|c|c|c|c|}
\hline \multicolumn{1}{|c|}{ Tissue ID } & $\begin{array}{c}\text { Isotype control } \\
\text { background }\end{array}$ & $\mathbf{3 +}$ & $\mathbf{2 +}$ & $\mathbf{1 +}$ & $\mathbf{0}$ \\
\hline Subcutaneous A-673 xenograft tumor & 0 & 20 & 40 & 40 & 0 \\
\hline Subcutaneous SJSA-1 xenograft tumor & 0 & 40 & 10 & 0 & 50 \\
\hline Subcutaneous MES-SA xenograft tumor & 0 & 20 & 10 & 0 & 70 \\
\hline
\end{tabular}

Figure 3. Expression of endosialin by immunohistochemisty in human sarcoma xenograft tumors implanted subcutaneously: A-673 Ewing's sarcoma (A), SJSA-1 osteosarcoma (B) and MES-SA uterine sarcoma (C). Endosialin immunohistochemical staining scores (D). 20X objective.

0 to $3+$ with $50 \%$ of the subcutaneous tumor and $20-40 \%$ of the lung colonies being endosialin-negative (Table II and Figs. 3 and 4). Because the anti-endosialin antibody used for IHC does not crossreact with mouse endosialin, the tumor stroma could not be assessed.

\section{Discussion}

The presence of endosialin expression in sarcoma cells was described in the first endosialin publication in 1992, with the anecdotal report of FB5 immunoreactivity in a subset of 
A
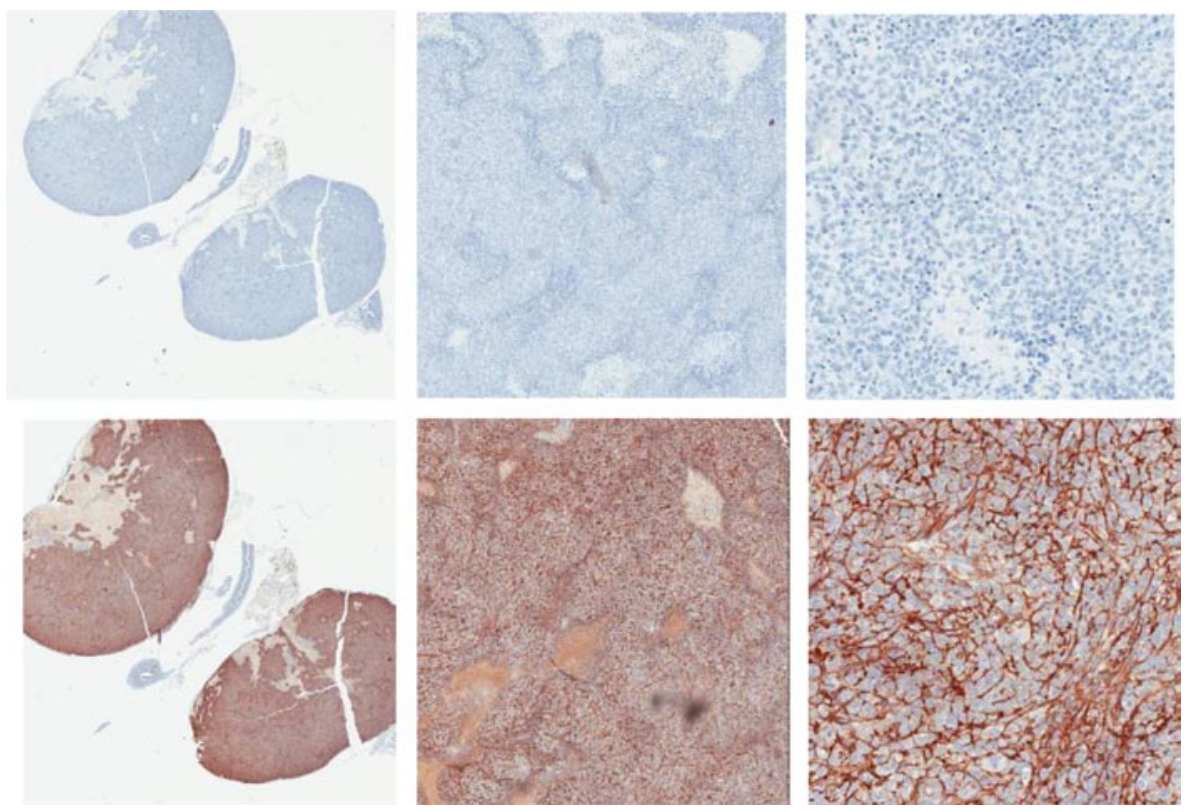

B
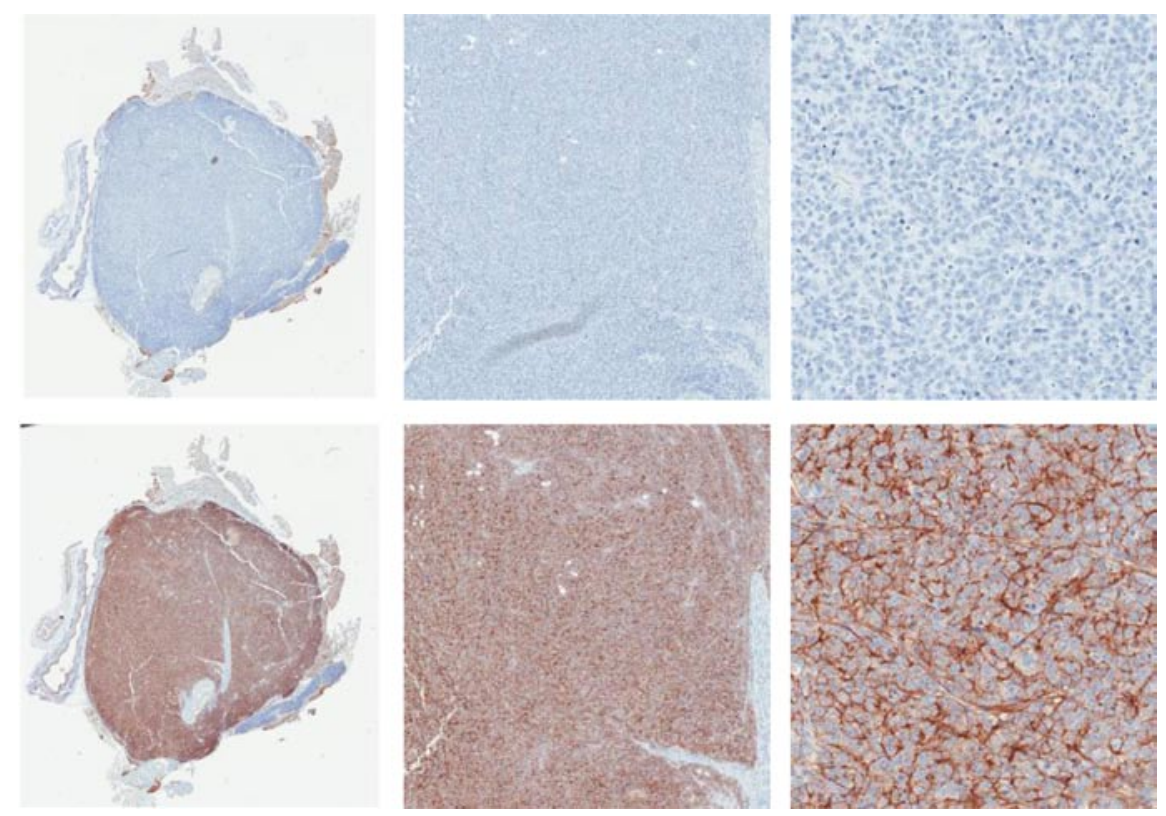

C
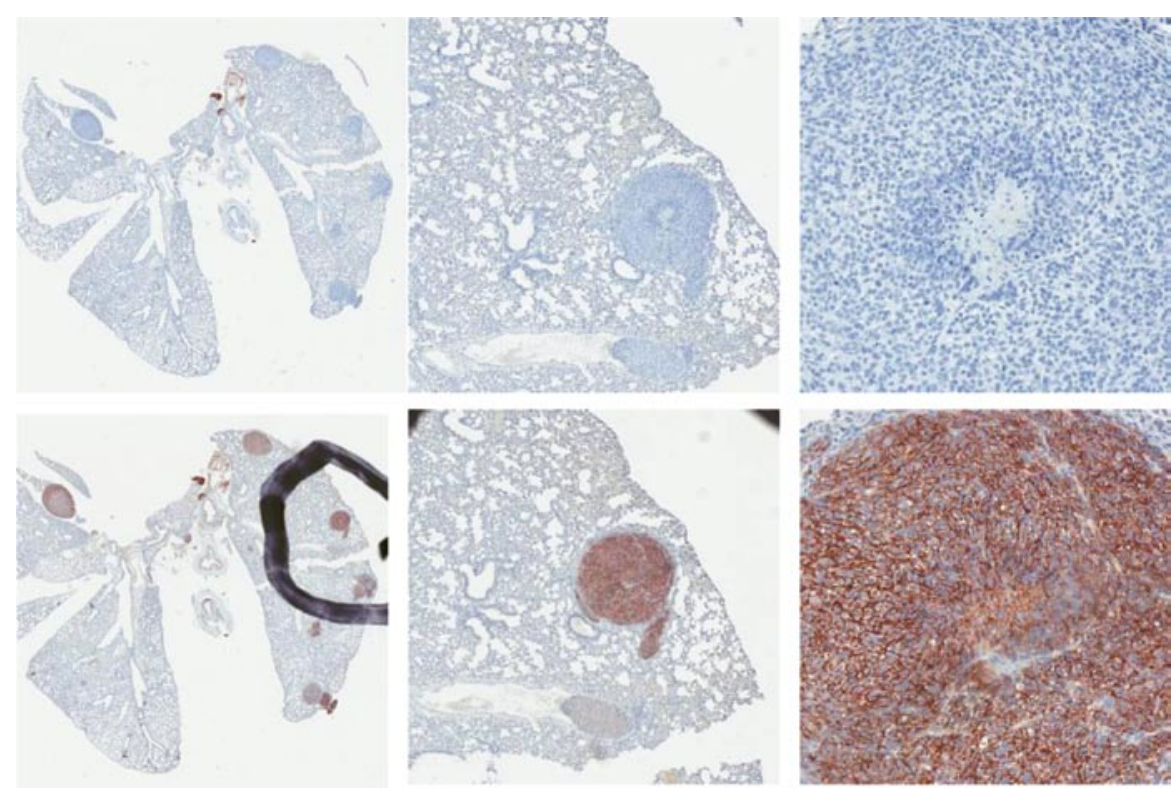

Figure 4. Expression of endosialin by immunohistochemisty in human sarcoma cells injected intravenously. Dissemination of A-673 Ewing's sarcoma to ovary (A), tracheobronchial lymph node (B), lung (C). 
D
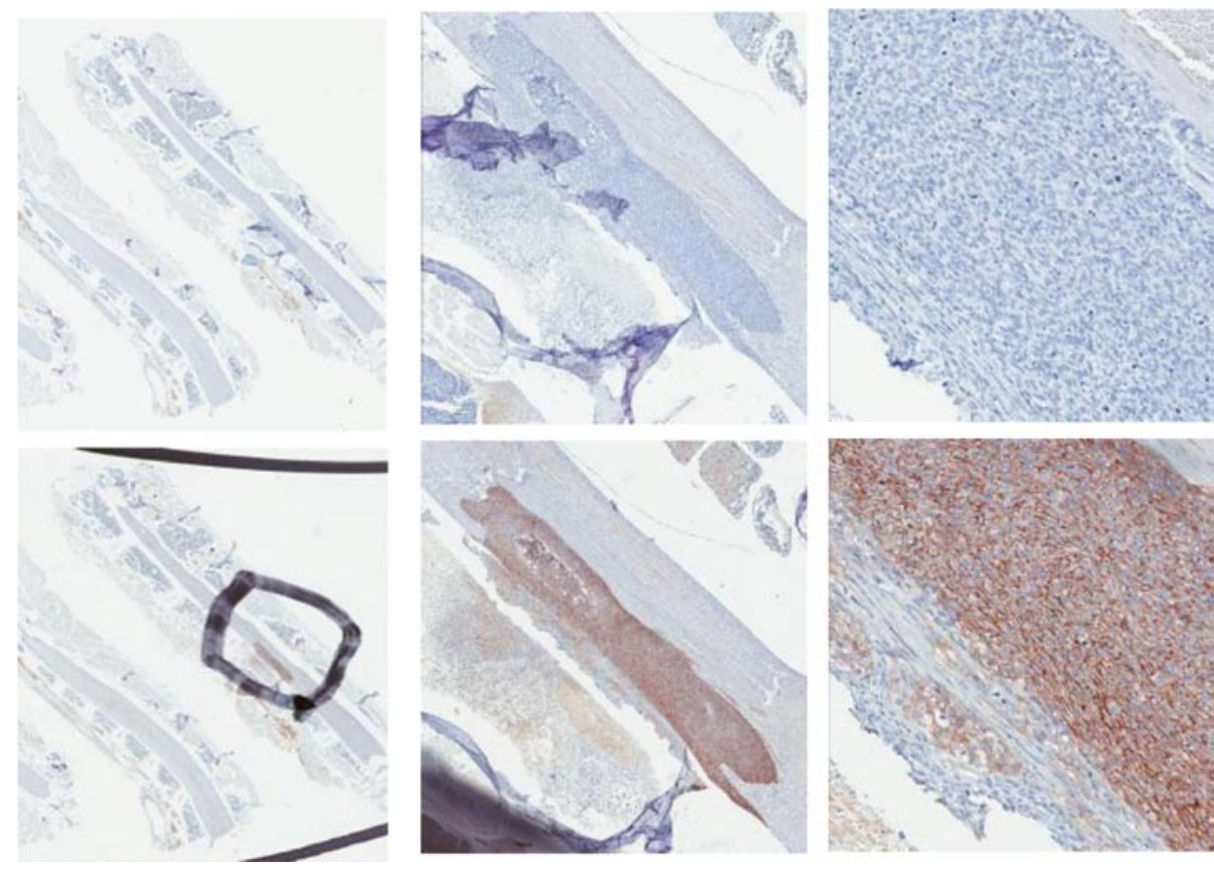

E
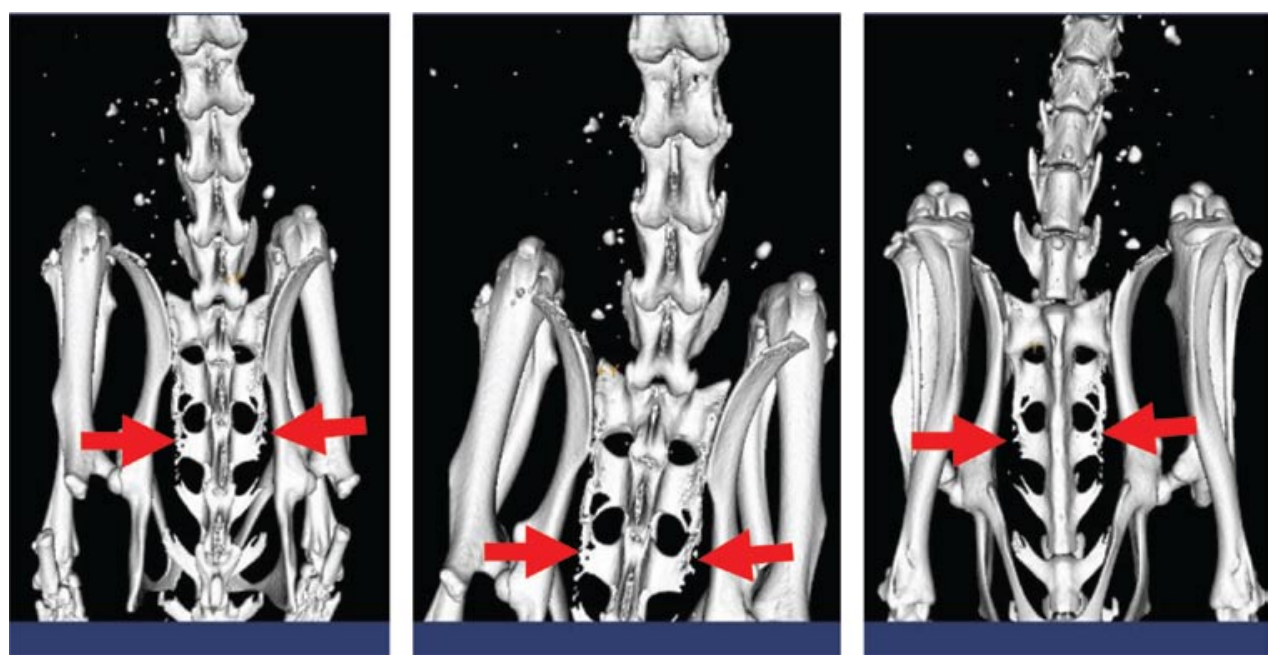

F
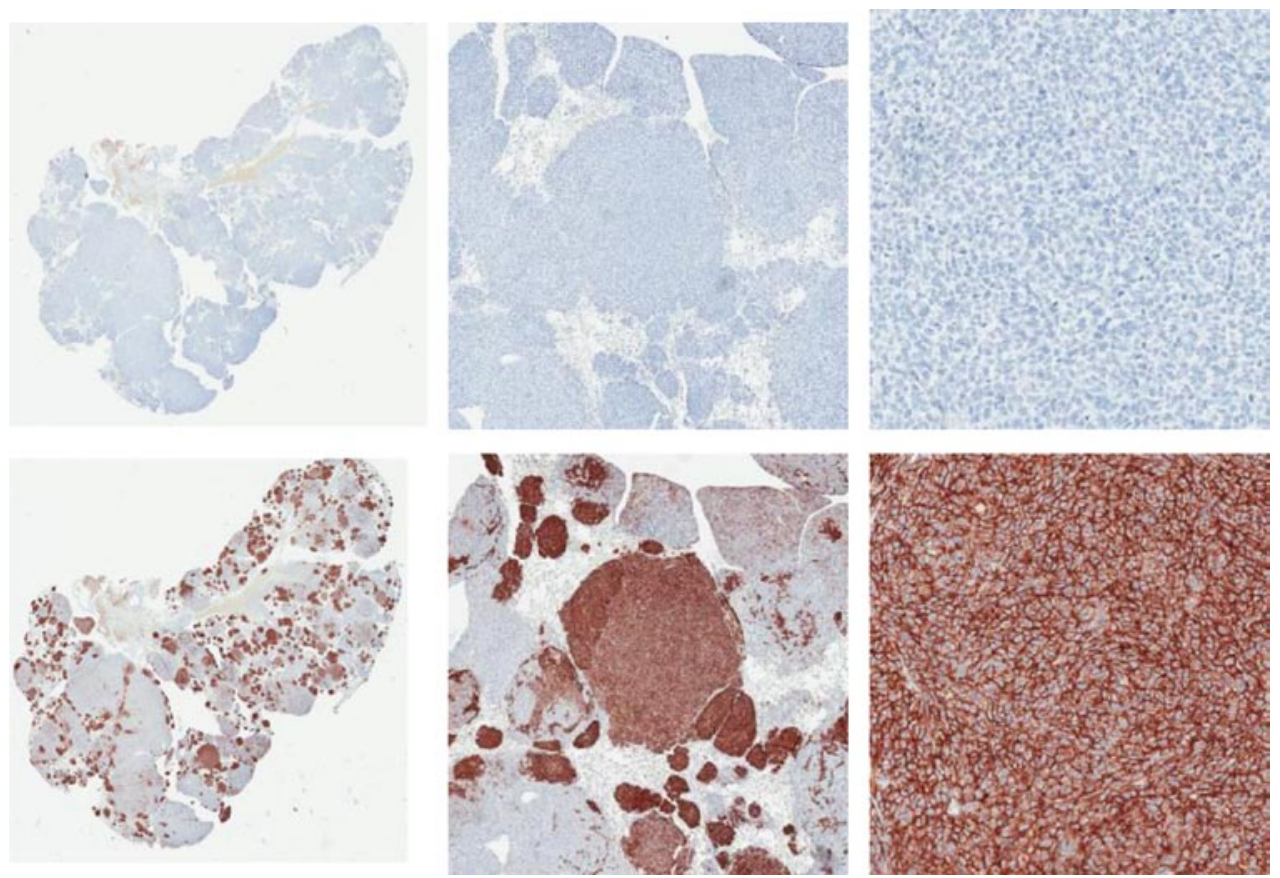

Figure 4 (continued). Vertebrae (D) and micro-CT imaging showing bone degradation (arrows) (E). Dissemination of SJSA-1 osteosarcoma to lung (F). 
G

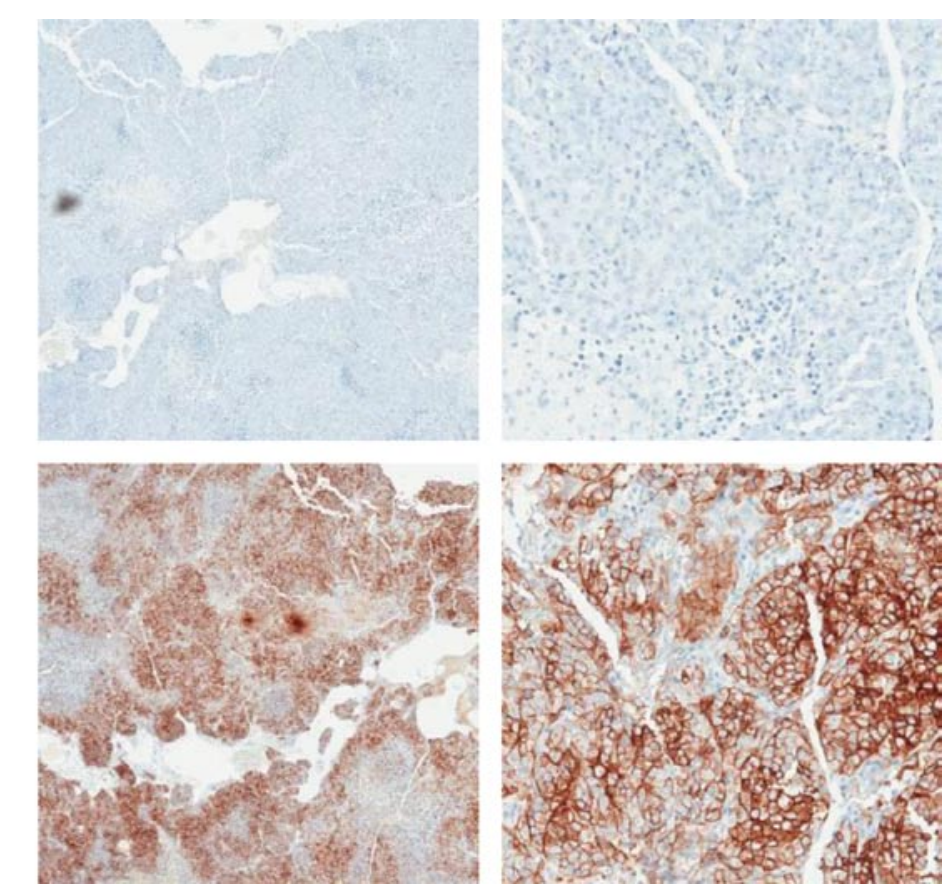

$\mathbf{H}$

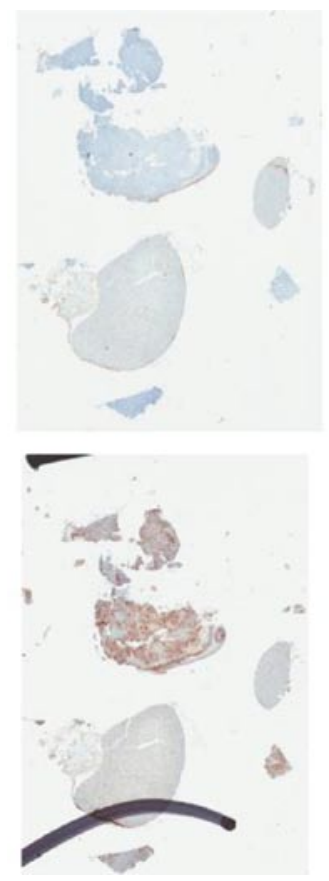

\begin{tabular}{|c|c|c|c|c|c|c|}
\hline \multirow{2}{*}{ Cell line } & \multirow{2}{*}{ Tissue Type \& Xenograft } & \multirow{2}{*}{ Histologic Review } & \multicolumn{4}{|c|}{$\begin{array}{c}\text { Tumor cells intensity } \& \\
\% \text { coverage }\end{array}$} \\
\hline & & & $3+$ & $2+$ & $1+$ & $\mathbf{0}$ \\
\hline A-673 & Lung & Tumor in lung & 100 & 0 & 0 & 0 \\
\hline A-673 & Ovary & Tumor mass $\&$ adjacent uterus & 100 & 0 & 0 & 0 \\
\hline A-673 & Spine & Tumor in spinal cord \& bone & 40 & 20 & 40 & 0 \\
\hline A-673 & Heart/tracheobronchial LN & Tumor \& heart & 100 & 0 & 0 & 0 \\
\hline A-673 & Lung & Tumor in lung & 40 & 60 & 0 & 0 \\
\hline A-673 & Limb mass/bronchial LN & Tumor nodule & 80 & 20 & 0 & 0 \\
\hline A-673 & Lung & Scant tumor in lung & 100 & 0 & 0 & 0 \\
\hline A-673 & Neck mass/submandibular LN & Tumor nodule & 80 & 20 & 0 & 0 \\
\hline SJSA-1 & Lung & Tumors in lung & 30 & 10 & 20 & 40 \\
\hline SJSA-1 & Lung & Tumors in lung & 10 & 20 & 30 & 40 \\
\hline SJSA-1 & Lung & Tumors in lung & 30 & 10 & 40 & 20 \\
\hline SJSA-1 & Lung & Tumors in lung & 30 & 20 & 30 & 20 \\
\hline MES-SA & Kidney & Tumor \& kidney & 80 & 0 & 10 & 10 \\
\hline
\end{tabular}

Figure 4 (continued). Dissemination of MES-SA uterine sarcoma to adrenal gland (G). Endosialin immunohistochemical staining scores (H). Bottom, anti-endosialin; top, isotype control. 0.5X objective (left); 4X objective (middle); 20X objective (right) (A, B, C, D, F, G). Dorsal (left); lumbar (middle); ventral (right) (E).

sarcomas (24). Later, unambiguous tumor cell FB5 immunoreactivity in clinical MFH and liposarcoma specimens was published (33). Subsequently, a survey of 86 paraffin-embedded clinical specimens of sarcoma, representing 9 subtypes, documented expression in malignant cells, stromal cells and vascular pericytes; 70/86 (81\%) specimens were positive for endosialin, and $44 / 86(51 \%)$ reached $\geq 50 \%$ coverage of immunoreactive tissue components (34). These reports raised awareness of endosialin as a tumor cell marker and therapeutic target in sarcoma.
However, these studies did not address the question of endosialin expression in advanced sarcoma. Over half of sarcoma patients develop metastatic disease, with lung being a common site of distant recurrence. Lung metastases are primarily treated with surgery, which is curative in only $15-30 \%$ of patients $(6,7)$, underscoring the need for new markers, targets and therapeutics to treat advanced disease. Using diagnostic reports for 86 clinical sarcoma specimens previously stained for endosialin, a retrospective analysis was performed to identify metastatic specimens and high-grade specimens. High grade 
is an adverse prognostic factor and an independent predictor of metastasis in sarcoma $(19,20)$. The analysis showed that endosialin can be detected in metastases and that levels of endosialin tend to be higher in high-grade specimens than in low-grade specimens in all sarcoma subtypes tested except liposarcoma. Our analysis also showed that endosialin levels tend to be higher in patients with tumor cell staining compared to patients with only vascular and/or stromal cell staining, and that endosialin expression in tumor cells was a more frequent event in high-grade disease compared to low-grade disease.

It is important to note that even though endosialin was detected in metastases and in high-grade disease, and although there was a positive correlation between endosialin levels and high-grade disease, some sarcomas remain endosialin-negative regardless of diagnostic grade or clinical stage, mandating a personalized medicine approach to targeting endosialin in sarcoma. Patients will need to be tested for endosialin expression to determine if endosialin-directed therapy is warranted.

In the broader characterization of endosialin-positive disease, endosialin was detected in tumors from patients of all ages and levels of endosialin did not correlate with patient age. There was a weak correlation between endosialin levels and gender with higher levels detected in female patients compared to male patients. The relationship is weak because not all measurements of endosialin levels produced a statistically significant association with gender. Nonetheless, these data suggest that the association between endosialin and gender could play a part in a future diagnostic or prognostic signature and warrants further investigation.

Having detected endosialin in clinical specimens of highgrade sarcoma and metastatic sarcoma, we modeled advanced disseminated sarcoma preclinically in vivo through intravenous injection of human sarcoma cells in nude mice. IHC of disseminated tumors showed maintenance of endosialin expression in three human sarcoma models, a Ewing's sarcoma model, an osteosarcoma model and a uterine sarcoma model, at all sites of dissemination including lung, adrenal gland, bone, lymph node and ovary. The data demonstrate that different organ microenvironments can support endosialin expression, which is consistent with the data obtained from clinical specimens and suggests that systemic anti-endosialin therapy may be beneficial in the advanced disease setting.

Although the biological function of endosialin is incompletely understood (24-34), our data support the notion that endosialin may play a role in malignancy. Most importantly, our results demonstrate that endosialin is expressed in sarcomas with poor prognosis and in advanced sarcoma, opening up the possibility that targeting endosialin could offer a therapeutic avenue for the more than $50 \%$ of children and adults suffering from sarcomas whose disease cannot be cured with existing treatment modalities $(6,7)$.

\section{Acknowledgements}

The anti-endosialin antibody was generated through a partnership with Kyowa Hakko Kirin Co., Ltd., Takasaki, Japan. The authors thank Dr Shiro Kataoka, Dr Nakayuki Honma, Dr Kazumasa Hasegawa, Dr Isao Ishida and Dr Tomoyuki Tahara. The authors also thank William Brondyk and Genzyme New Protein Therapeutics for purification of the antibody. The authors are Genzyme employees or were employees at the time the work was conducted.

\section{References}

1. Kotilingam D, Lev DC, Lazar AJ and Pollock RE: Staging soft tissue sarcoma: evolution and change. CA Cancer J Clin 56: 282-291, 2006.

2. Maki R: Sarcomas of Soft Tissue. Encyclopedia of Cancer. 2nd edition, 2003.

3. Osuna D and De Alava E: Molecular pathology of sarcomas. Rev Recent Clin Trials 4: 12-26, 2009.

4. Chou AJ, Geller DS and Gorlick R: Therapy for osteosarcoma: where do we go from here? Paediatr Drugs 10: 315-327, 2008.

5. Nijhuis PH, Schaapveld M, Otter R, Molenaar WM, van der Graaf WT and Hoekstra HJ: Epidemiological aspects of soft tissue sarcomas (STS)-consequences for the design of clinical STS trials. Eur J Cancer 35: 1705-1710, 1999.

6. Thornton K: Chemotherapeutic management of soft tissue sarcoma. Surg Clin North Am 88: 647-660, 2008.

7. Thornton K, Pesce CE and Choti MA: Multidisciplinary management of metastatic sarcoma. Surg Clin North Am 88: 661-672, 2008.

8. Verweij J: Soft tissue sarcoma trials: one size no longer fits all. J Clin Oncol 27: 3085-3087, 2009.

9. Demetri GD, von Mehren M, Antonescu CR, De Matteo RP, Ganjoo KN, Maki RG, et al: NCCN Task Force report: update on the management of patients with gastrointestinal stromal tumors. J Natl Compr Cancer Netw 8 (Suppl 2): S1-41; quiz S42-44, 2010.

10. Subbiah V, Anderson P, Lazar AJ, Burdett E, Raymond K and Ludwig JA: Ewing's sarcoma: standard and experimental treatment options. Curr Treat Options Oncol 10: 126-140, 2009.

11. Hernando E, Charytonowicz E, Dudas ME, et al: The AKT-mTOR pathway plays a critical role in the development of leiomyosarcomas. Nat Med 13: 748-753, 2007.

12. Baird K, Davis S, Antonescu CR, et al: Gene expression profiling of human sarcomas: insights into sarcoma biology. Cancer Res 65: 9226-9235, 2005.

13. Kolb EA and Gorlick R: Development of IGF-IR inhibitors in pediatric sarcomas. Curr Oncol Rep 11: 307-313, 2009.

14. Vistica DT, Hollingshead M, Borgel SD, Kenney S, Stockwin LH, Raffeld M, Schrump DS, Burkett S, Stone G, Butcher DO and Shoemaker RH: Therapeutic vulnerability of an in vivo model of alveolar soft part sarcoma (ASPS) to antiangiogenic therapy. J Pediatr Hematol Oncol 31: 561-570, 2009.

15. Hu-Lieskovan S, Heidel JD, Bartlett DW, Davis ME and Triche TJ: Sequence-specific knockdown of EWS-FLI1 by targeted, nonviral delivery of small interfering RNA inhibits tumor growth in a murine model of metastatic Ewing's sarcoma. Cancer Res 65: 8984-8992, 2005.

16. Nguyen DX, Bos PD and Massagué J: Metastasis: from dissemination to organ-specific colonization. Nat Rev Cancer 9: 274-284, 2009.

17. Mareel M, Oliveira MJ and Madani I: Cancer invasion and metastasis: interacting ecosystems. Virchows Arch 454: 599-622, 2009.

18. Monteiro J and Fodde R: Cancer stemness and metastasis: therapeutic consequences and perspectives. Eur J Cancer 46: 1198-1203, 2010.

19. Pisters PW, Leung DH, Woodruff J, Shi W and Brennan MF: Analysis of prognostic factors in 1,041 patients with localized soft tissue sarcomas of the extremities. J Clin Oncol 14: 1679-1689, 1996.

20. Coindre JM, Terrier P, Guillou L, Le Doussal V, Collin F, Ranchère D, Sastre X, Vilain MO, Bonichon F and N'Guyen Bui B: Predictive value of grade for metastasis development in the main histologic types of adult soft tissue sarcomas: a study of 1240 patients from the French Federation of Cancer Centers Sarcoma Group. Cancer 91: 1914-1926, 2001.

21. Abed R, Grimer RJ, Carter SR, Tillman RM, Abudu A and Jeys L: Soft-tissue metastases: their presentation and origin. J Bone Joint Surg Br 91: 1083-1085, 2009.

22. Gadd MA, Casper ES, Woodruff JM, McCormack PM and Brennan MF: Development and treatment of pulmonary metastases in adult patients with extremity soft tissue sarcoma. Ann Surg 218: 705-712, 1993.

23. Vezeridis MP, Moore R and Karakousis CP: Metastatic patterns in soft-tissue sarcomas. Arch Surg 118: 915-918, 1983. 
24. Rettig WJ, Garin-Chesa P, Healey JH, Su SL, Jaffe EA and Old LJ: Identification of endosialin, a cell surface glycoprotein of vascular endothelial cells in human cancer. Proc Natl Acad Sci USA 89: 10832-10836, 1992.

25. St. Croix B, Rago C, Velculescu V, Traverso G, Romans KE Montgomery E, Lal A, Riggins GJ, Lengauer C, Vogelstein B and Kinzler KW: Genes expressed in human tumor endothelium. Science 289: 1197-1202, 2000.

26. Bagley RG: Endosialin: from vascular target to biomarker for human sarcomas. Biomark Med 3: 589-604, 2009.

27. Lax S, Hou TZ, Jenkinson E, Salmon M, MacFadyen JR, Isacke CM, Anderson G, Cunningham AF and Buckley CD: CD248/endosialin is dynamically expressed on a subset of stromal cells during lymphoid tissue development, splenic remodeling and repair. FEBS Lett 581: 3550-3556, 2007.

28. MacFadyen J, Savage K, Wienke D and Isacke CM: Endosialin is expressed on stromal fibroblasts and CNS pericytes in mouse embryos and is downregulated during development. Gene Expr Patterns 7: 363-369, 2007.

29. Virgintino D, Girolamo F, Errede M, Capobianco C, Robertson D, Stallcup WB, Perris R and Roncali L: An intimate interplay between precocious, migrating pericytes and endothelial cells governs human fetal brain angiogenesis. Angiogenesis 10: 35-45, 2007.

30. Huber MA, Kraut N, Schweifer N, Dolznig H, Peter RU, Schubert RD, Scharffetter-Kochanek K, Pehamberger H and Garin-Chesa P: Expression of stromal cell markers in distinct compartments of human skin cancers. J Cutan Pathol 33 $145-155,2006$

31. Nanda A, Karim B, Peng Z, Liu G, Qiu W, Gan C, Vogelstein B St Croix B, Kinzler KW and Huso DL: Tumor endothelial marker 1 (Tem1) functions in the growth and progression of abdominal tumors. Proc Natl Acad Sci USA 103: 3351-3356, 2006.

32. Tomkowicz B, Rybinski K, Sebeck D, Sass P, Nicolaides NC, Grasso L and Zhou Y: Endosialin/TEM-1/CD248 regulates pericyte proliferation through PDGF receptor signaling. Cancer Biol Ther 9: 1-8, 2010

33. Dolznig H, Schweifer N, Puri C, Kraut N, Rettig WJ, Kerjaschki D and Garin-Chesa P: Characterization of cancer stroma markers: in silico analysis of an mRNA expression database for fibroblast activation protein and endosialin. Cancer Immun 5: 1-8, 2005.

34. Rouleau C, Curiel M, Weber W, Smale R, Kurtzberg L, Mascarello J, Berger C, Wallar G, Bagley R, Honma N, Hasegawa K, Ishida I, Kataoka S, Thurberg BL, Mehraein K, Horten B, Miller G and Teicher BA: Endosialin protein expression and therapeutic target potential in human solid tumors: sarcoma versus carcinoma. Clin Cancer Res 14: 7223-7236, 2008.
35. Maheshwari AV and Cheng EY: Ewing sarcoma family of tumors. J Am Acad Orthop Surg 18: 94-107, 2010.

36. Joensuu H: Gastrointestinal stromal tumor (GIST). Ann Oncol 17 (Suppl 10): 280-286, 2006.

37. Kazmi SA, Perry A, Pressey JG, Wellons JC, Hammers Y and Palmer CA: Primary Ewing sarcoma of the brain: a case report and literature review. Diagn Mol Pathol 16: 108-111, 2007.

38. Fernández EL, Plasencia LD, Palma JP and Pallares AC: Giant ulcerated pleomorphic liposarcoma of the chest wall. J Thorac Oncol 2: 1126-1127, 2007.

39. Urabe M, Mizobuchi N, Funabiki H, Seki E, Okada T and Sakakibara N: A case of liposarcoma originating in the chest wall. Nippon Geka Hokan 64: 131-138, 1995.

40. Loddenkemper C, Pérez-Canto A, Leschber G and Stein H: Primary dedifferentiated liposarcoma of the lung. Histopathology 46: 710-712, 2005.

41. Fukai R, Fukumura Y and Suzuki K: A dedifferentiated liposarcoma of the anterior mediastinum. Int J Clin Oncol 14: 174-177, 2009.

42. Greif J, Marmor S, Merimsky O, Kovner F and Inbar M: Primary liposarcoma of the mediastinum. Sarcoma 2: 205-207, 1998.

43. Uenotsuchi T, Imafuku S, Moroi Y, Urabe K and Furue M: Large subcutaneous liposarcoma arising from the chest wall. Eur J Dermatol 15: 43-45, 2005.

44. Dei Tos AP: Liposarcoma: new entities and evolving concepts. Ann Diagn Pathol 4: 252-266, 2000.

45. Park SW, Kim HJ, Lee JH and Ko YH: Malignant fibrous histiocytoma of the head and neck: CT and MR imaging findings. AJNR Am J Neuroradiol 30: 71-76, 2009.

46. Geary TR, Maclennan AC and Irwin GJ: Hypertrophic osteoarthropathy in primary liver rhabdomyosarcoma. Pediatr Radiol 34: $250-252,2004$

47. Huang FC, Eng HL, Chen CL and Ko SF: Primary pleomorphic rhabdomyosarcoma of the liver: a case report. Hepatogastroenterology 50: 73-76, 2003.

48. McArdle JP, Hawley I, Shevland J and Brain T: Primary rhabdomyosarcoma of the adult liver. Am J Surg Pathol 13: 961-965, 1989.

49. Mirzoyan M, Muslimani A, Setrakian S, Swedeh M and Daw HA: Primary pleuropulmonary synovial sarcoma. Clin Lung Cancer 9: 257-261, 2008.

50. Jiang J, Zhou J and Ding W: Primary pulmonary synovial sarcoma, a rare primary lung neoplasm: two case reports and review of the current literature. Respirology 13: 748-750, 2008. 